\title{
El otro Madrid: el chabolismo que no cesa. Actuación autonómica en políticas de realojamiento e integración social 1997-2010
}

\section{Another Madrid: the not stop growing shanty towns. Regional rehousing and social integration policies, $1997-2010$}

\author{
María Jesús Lago Ávila*
}

\section{LA ERRADICACIÓN DEL CHABOLISMO EN MADRID: LA NECESARIA COLABORACIÓN ENTRE ADMINISTRACIONES}

1.1. El desmantelamiento de los grandes núcleos de chabolas de la capital.

Las actuaciones contra el chabolismo y la marginalidad residencial llevadas a cabo en Madrid desde el surgimiento de la democracia en 1978 hasta 1986 se concretaron en la mayor actuación contra la infravivienda realizada en España hasta el momento y conocida como Operación Barrios en Remodelación que afectó a 28 barrios y realojó a 1.490 .000 personas. Dicha actuación supuso la construcción de 38.540 viviendas, con una inversión de 310 millones de pesetas, y se extendió sobre 8.378 hectáreas de 12 distritos de la capital, como muestra la figura 1.

Pero el programa de Barrios en Remodelación únicamente incluyó en sus actuaciones a 644 familias gitanas chabolistas que representaban en aquel momento el 1,8\% de los realojamientos del programa, como muestra la figura 2.

Concluida la actuación, el chabolismo dejo de ser considerado en Madrid como un fenómeno amplio que afectaba a una gran variedad de grupos sociales para circunscribirse casi en exclusiva a un problema que sufría la población gitana.

\footnotetext{
*Universidad CEU San Pablo, Departamento de Historia y Pensamiento lagavi@ceu.es.
} 
FIGURA 1

VIVIENDAS DE REALOJAMIENTO CONSTRUIDAS DENTRO DEL PROGRAMA "BARRIOS EN REMODELACIÓN POR DISTRITO"

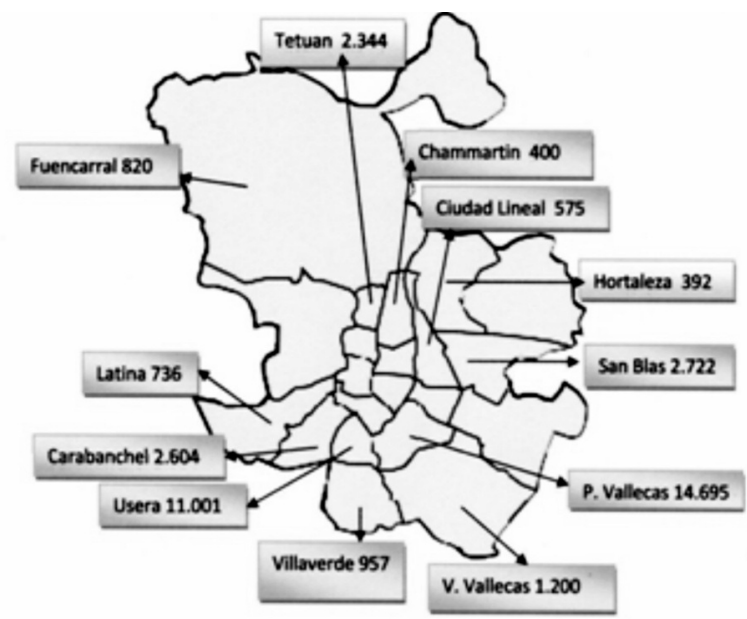

Fuente: Elaboración propia a partir de las memorias del MOPU 1985.

FIGURA 2

NÚMERO DE FAMILIAS GITANAS REALOJADAS DENTRO DEL PROGRAMA "BARRIOS EN REMODELACIÓN POR DISTRITO Y ASENTAMIENTO"

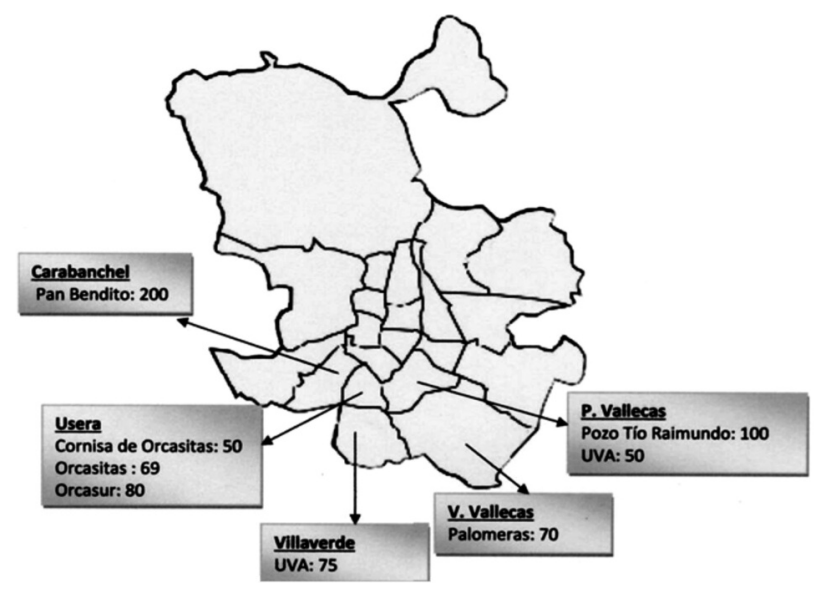

Fuente: Elaboración propia a partir de los datos de Noguez Saez, 2010: "Exclusión residencial y políticas públicas. El caso de la minoría gitana en Madrid". Tesis doctoral inédita. Universidad de Granada, Departamento de Antropología. 
El proceso de concentración étnica de la marginalidad residencial en la minoría gitana en la ciudad de Madrid fue tan importante que en el censo de 1979, realizado por el Ayuntamiento de Madrid precisamente para el Programa de Remodelación de Barrios, las chabolas ocupadas por gitanos en la capital solo representaban el 52,8\% mientras que cinco años después, en 1984, suponían ya el 93\%, siendo en algunos distritos el único colectivo que aún vivía en chabolas, como muestra la figura 3.

Los datos evidenciaban que la mayoría de las familias chabolistas no gitanas habían conseguido acceder a una vivienda normalizada pero no así una parte importante de los gitanos residentes en las mismas áreas. La gran actuación urbanística y residencial que supuso el Programa Barrios en Remodelación dejó al margen a más de 2.600 familias gitanas para las que fue necesario en años posteriores crear programas específicos orientados no sólo a su realo-

FIGURA 3

PROCESO DE CONCENTRACIÓN ÉTNICA DEL CHABOLISMO MADRILEÑO

\section{Evolución del porcentaje de familas gitanas en chabolas por distrito entre los años 1979 y 1984}

$1979 \square 1984$

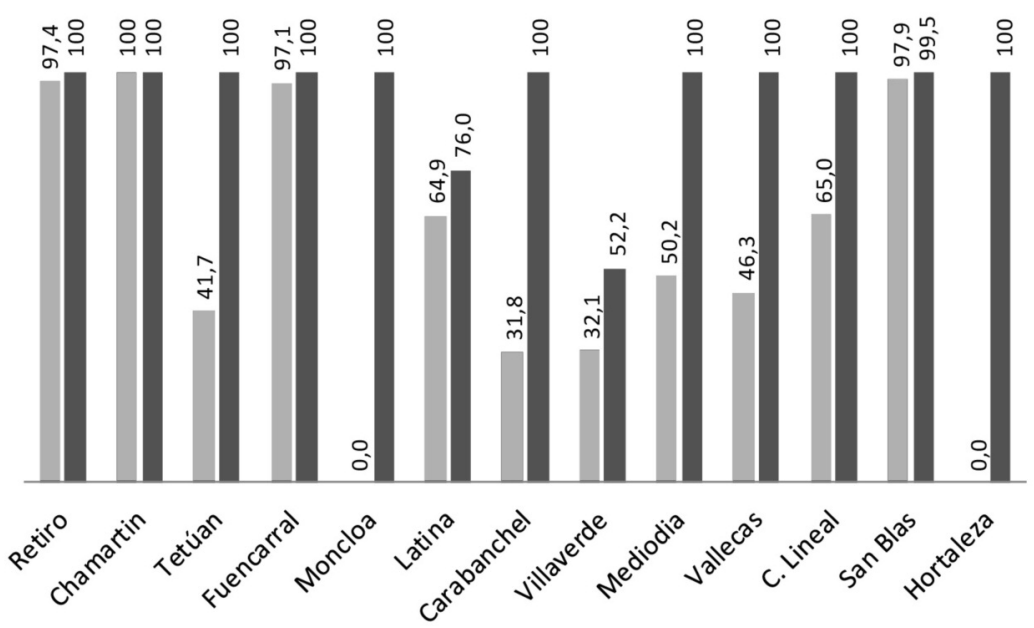

Fuente: Elaboración propia a partir de los datos de Noguez Saez, 2010: "Exclusión residencial y políticas públicas. El caso de la minoría gitana en Madrid". Tesis doctoral inédita. Universidad de Granada, Departamento de Antropología. 
jamiento sino también a su integración social. La necesidad de una intervención dirigida únicamente a este colectivo se plasmó en el Plan de Desarrollo Gitano de 1979.

La población gitana era continuamente relegada a un último puesto en este tipo de actuaciones por sus problemas de integración social y sus enfrentamientos con otros grupos que residían en el entorno. Un importante número de ellas habían generado conflictos en anteriores actuaciones y cuando se les unieron, a partir de los años setenta, otras familias de origen portugués y rumano, con situaciones de deterioro social aún peores, la realidad se hizo tan compleja que no se podía resolver sólo con medidas de carácter residencial o urbanístico.

La cronicidad de un chabolismo cada vez más marginal forzó necesariamente a la administración al diseño de propuestas de realojamiento basadas en políticas transversales de intervención y en las que era imprescindible la necesaria colaboración entre administraciones para coordinar esfuerzos.

En el contexto descrito, en enero de 1984 se desarrolla la Propuesta del Área de Infraestructura y Urbanismo del Ayuntamiento de Madrid para la Erradicación del Chabolismo Gitano (Propuesta AUI) que se denominó Plan de Acciones para la Erradicación del Chabolismo Gitano. Su objetivo era, no sólo mejorar la calidad de los alojamientos de los chabolistas gitanos, sino integrarlos socialmente e «incorporar a los gitanos al resto de la sociedad», tal como se indicaba en el documento.

Todas las propuestas que se fueron planteando durante aquellos años iban en esa línea. La Propuesta AUI tenía la pretensión de erradicar el chabolismo ${ }^{1}$ madrileño, ya casi exclusivamente gitano, en un plazo máximo de 4 años (1984-1988) y realojar al 80\% de sus inquilinos. Las familias iban a ser trasladadas a viviendas de tipología especial como situación transitoria (viviendas unifamiliares con patio) y/o a poblados especiales de viviendas prefabricadas para familias nómadas (AUI, 1984, p. 45). Para ello se construirían 300 viviendas anuales hasta llegar a los 1.200 alojamientos. Las dos administraciones Central y Autonómica se comprometieron a colaborar en la batalla contra el chabolismo de la capital. Y de hecho, se vieron obligadas a actuar de inmediato por la conflictividad social de núcleos como San Blas y Vicálvaro.

\footnotetext{
${ }^{1}$ Ya desde el documento de 1984, en la propuesta AUI, se especificaba claramente qué se entendía por chabola y qué tipo de población alojaban estos núcleos de ambiente físico y social degradado y carentes de todo tipo de servicios básicos (agua, electricidad, etc.) así como las intervenciones a realizar.
} 
En aquellos años en el Ayuntamiento de Madrid estaba como alcalde Tierno Galván (1979-1986) y en la Comunidad de Madrid como presidente Joaquín Legina (1983-1995), ambos pertenecientes al mismo grupo político y con una especial sensibilidad hacia estos temas. La colaboración en estos años fue tarea fácil. España comenzaba a mejorar económicamente tras la crisis de los setenta. La capital crecía y era necesario erradicar el chabolismo de su territorio.

En ese momento se estaba elaborando el Plan General de Ordenación Urbana de la capital que se aprobaría en 1985. El Plan debía actuar sobre muchos de los terrenos ocupados por chabolas. El coste estimado de la intervención superaba los 3.500 millones de pesetas del momento pero era una inversión imprescindible para permitir el posterior desarrollo urbano de la ciudad. La mayoría de los terrenos ocupados por las chabolas iban a ser destinados a infraestructuras de comunicaciones, zonas verdes, espacio residencial o incluso espacio industrial.

Las figuras de planeamiento urbanístico que afectaron posteriormente a estos espacios fueron muy variadas. En 17 de los asentamientos, de los 54 existentes en aquel momento en la capital, se optó por reordenar estas áreas a través de Planes de Reforma Interior. Esta figura se utilizó sólo en aquellos núcleos de chabolas localizados en áreas urbanas consolidadas dónde eran pequeños enclaves de marginalidad. Fue el caso de los asentamientos de Electrodo (distrito de Retiro), Campamento (distrito de Chamartín) o Crisantemo (distrito de Tetuán).

En otras ocasiones la figura elegida fue la del Estudio de Detalle, como en los asentamientos de Hierro (distrito de Arganzuela), Rodríguez Jaén (distrito de Chamartín), Julián Pando (distrito de Latina), Eduardo Morales (distrito de Ciudad Lineal), o Arenero (distrito de Vicálvaro). El núcleo de Campamento (Chamartín), por ejemplo, se asentaba sobre terrenos de propiedad pública vinculados a las zonas de equipamiento y servicios de la cercana estación ferroviaria de Chamartín. Pero la figura que se usó con mayor frecuencia para ordenar muchas de estas zonas fue la de Área de Planeamiento Diferenciado.

Algunos núcleos, según el Plan General de Ordenación Urbana de 1985, se localizaban sobre terrenos destinados a parque urbano o suburbano. Fueron los casos de los asentamientos de Chorrillo (Tetuán), La Veguilla (Monclóa), La Mica y Los Caprichos (Latina), Arroyo de Valdecellada y Armengot (Carabanchel), Rancho del Cordobés (Usera), parte del núcleo de La Celsa (Puente de Vallecas), Cementerio (Moratalaz), o Manoteras (Hortaleza). Otros se levantaban sobre áreas destinadas a infraestructuras de comunicación como el asentamiento de José López (Fuencarral) que se ubicaba sobre lo que posteriormente sería el trazado de la Avenida de la Ilustración (cierre norte de la M-30). 
Muchos de ellos habían crecido en áreas calificadas como suelo urbanizable programado sobre las que posteriormente se desarrollaron Planes Parciales de Actuación. Estos fueron los casos de núcleos como los de Cruz del Cura (Fuencarral) sobre cuyos terrenos creció la extensión del barrio de Mirasierra, Torregrosa (Villaverde), Av. De Guadalajara (San Blas) en cuyo espacio se desarrolló el barrio residencial de Las Rosas, o el núcleo de Los Focos (Vicálvaro).

El propietario de la mayoría de los terrenos dónde se localizaba, salvo en contadas excepciones, era el Ayuntamiento de Madrid. El motivo de la ocupación mayoritaria de suelo de titularidad pública era sin duda que se trataba de los únicos espacios vacantes en la ciudad dónde con el paso de los años y la lentitud de la administración en los procesos de desahucio los chabolistas consolidaron su situación residencial.

\subsection{La necesidad de crear un Consorcio en 1986 para la erradicación del chabolismo gitano}

Como hemos indicado la poca efectividad de la Propuesta AUI y la necesidad de liberar suelo para el crecimiento de la ciudad obligó en 1986 a crear un Consorcio para el Realojamiento de la Población Marginada (CPM) integrado por el Ayuntamiento de la capital y por la Comunidad Autónoma. El 10 de enero de 1986 ambas instituciones firman un acuerdo de colaboración con el objetivo de ganar la batalla al chabolismo e integrar socialmente a sus habitantes con el desarrollo de políticas de intervención social. Las actuaciones del Consorcio se centrarían en:

- Realojar a las familias afectadas: aquellas que estuvieran preparadas serían realojadas directamente en pisos distribuidos por barriadas cercanas. Las que necesitaran un periodo transitorio de adaptación pasarían unos años en barrios de tipología especial (prefabricados o casas bajas con patio) hasta finalmente poder acceder a vivienda en altura. Se intentaría respetar al máximo la cercanía de las nuevas viviendas con los antiguos sentamientos para no romper los lazos, afectivos y relaciones y laborales de estas familias con su entorno.

- Integrar a las familias censadas: a través de medidas de intervención social y laboral. Se hizo especial hincapié en la escolarización de los niños y su normalización académica, luchando contra el absentismo escolar a través de la concienciación de sus progenitores de la necesidad de formación de sus hijos. Se desarrollaron programas de capacitación laboral 
en profesiones a las que pudieran incorporarse, sobre todo la población joven (formación en oficios relacionados con la construcción, con la mecánica, etc.) intentando respetar al máximo sus oficios tradicionales. Se llevarían a cabo campañas de alfabetización de adultos, se normalizo su situación sanitaria, etc.

El Consorcio comenzó a desarrollar sus actuaciones en 1986. En los primeros cinco años sus artífices y ejecutores fueron ajustando las intervenciones a partir de las experiencias que iban teniendo. Se fueron cambiando los planteamientos iniciales y se establecieron los fundamentos teóricos y prácticos de las intervenciones a posteriori.

Los inmediatos siguientes cinco años, hasta 1995, fueron años muy difíciles para el Consorcio, se llegó a hablar de crisis institucional. Muchos eran los problemas pero quizá uno de los más importantes fue que hasta 1991 no se pudo hacer ningún seguimiento social, ni asistencial, a las familias realojadas en pisos por falta de medios lo que complico y provoco el fracaso de un gran número de realojos.

En 1991 la presión social obligo a desarrollar el proyecto denominado "Seguimiento de familias realojadas en viviendas en altura" que establecía como objetivo fundamental su integración en la comunidad de vecinos en la que se les realojaba. Sin duda el fallo de la actuación fue que los problemas se iban solucionando a medida que se producían, sin una planificación previa, en una política de "parches», según señalaban los propios afectados. Entre 1995 y 1998 la situación se complicó aún más y finalmente en 1998, ante la imposibilidad de solucionar todos los problemas que se arrastraban, Ayuntamiento y Comunidad toman la decisión de disolver el Consorcio.

La crisis del Consorcio se produjo entre 1991 y 1995 y fue fruto en gran medida del incumplimiento de las expectativas creadas a la población afectada. Las familias chabolistas censadas creyeron que este organismo les daría rápidamente una vivienda con arreglo a sus necesidades pero la realidad les mostró que el proceso era lento y complejo. El conflicto de Villaverde de 1991 ejemplifico esta circunstancia y desencadeno graves enfrentamientos internos dentro del propio Consorcio. La falta de presupuesto dificultó y ralentizó los realojos enfrentando al Ayuntamiento y a la Comunidad de Madrid.

Aunque las actuaciones propuestas por el Consorcio deberían haber sido únicamente técnicas, para algunos autores, tuvieron una fuerte carga ideológica y política que nunca debería haberse producido y que marco el proceso de crisis final de la institución y en gran medida su disolución (Noguez Saez, 2010). 
A pesar de todo es necesario reconocer que tanto la creación del Consorcio como su gestión son el mejor ejemplo de la necesaria cooperación entre entidades públicas. Las actuaciones del Consorcio no hubieran sido posibles sin dicha colaboración ya que este organismo pudo hacerse cargo del realojamiento de 2.674 familias a partir de las aportaciones de viviendas de la EMV (organismo del Ayuntamiento) y el IVIMA (organismo de la Comunidad).

La realidad que tuvo que abordar el Consorcio era muy complicada. De entre todas las familias a realojar 568 debían ser trasladadas a pisos en alquiler repartidos por la ciudad de Madrid (procedentes de la EMV, del IVIMA y del mercado libre). El resto se localizarían en alojamientos transitorios (viviendas unifamiliares con patio, denominados Barrios de Tipología Especial) y en campamentos provisionales de prefabricados (para poblaciones con comportamientos seminómadas dedicados a actividades de compraventa, venta de saneamientos, recogida de chatarra, etc.).

En un principio el concepto de las viviendas de transición partía de la idea bondadosa de adaptarse a las necesidades reales de la población afectada. La propuesta era que las familias residieran en ellas sólo unos años durante un periodo transitorio de integración social y laboral que les permitiera trasladarse posteriormente a una vivienda en altura en otras barriadas en comunidades de vecinos no gitanos. Los barrios de transición contaban con escuelas infantiles, puestos de atención sanitaria, talleres de capacitación profesional, aulas de alfabetización y asistentes sociales. Pero la permanencia de los afectados en estos barrios por más de diez años, anuló con la idea inicial del proyecto y estas áreas acabaron convirtiendo en auténticos guetos de marginalidad y pobreza.

\subsection{Los desencuentros entre administraciones y la crisis del Consorcio}

Las actividades del Consorcio fueron posibles gracias a la firma de un convenio de colaboración en 1986 entre Ayuntamiento, Comunidad de Madrid y Estado Central por el que se comprometían a aportar 15 millones de pesetas anuales cada una de ellas durante los primeros seis años. El capital era imprescindible para la elaboración de un censo de chabolas y el comienzo del funcionamiento de su Gerencia. El censo identifico 2.192 familias (1.608 alojadas en chabolas y 584 en prefabricados antiguos muy deteriorados) localizadas en 16 distritos, en su gran mayoría del sur y sureste de la capital, como muestra la figura 4.

En el mismo convenio se especificaba una primera fase experimental de dos años de colaboración entre entidades públicas, antes de firmar un segundo convenio de continuidad. Con la firma del segundo convenio en 1988 comen- 
FIGURA 4

LOCALIZACIÓN DE LOS ASENTAMIENTOS CHABOLISTAS CENSADOS POR EL CONSORCIO EN 1986 EN MADRID

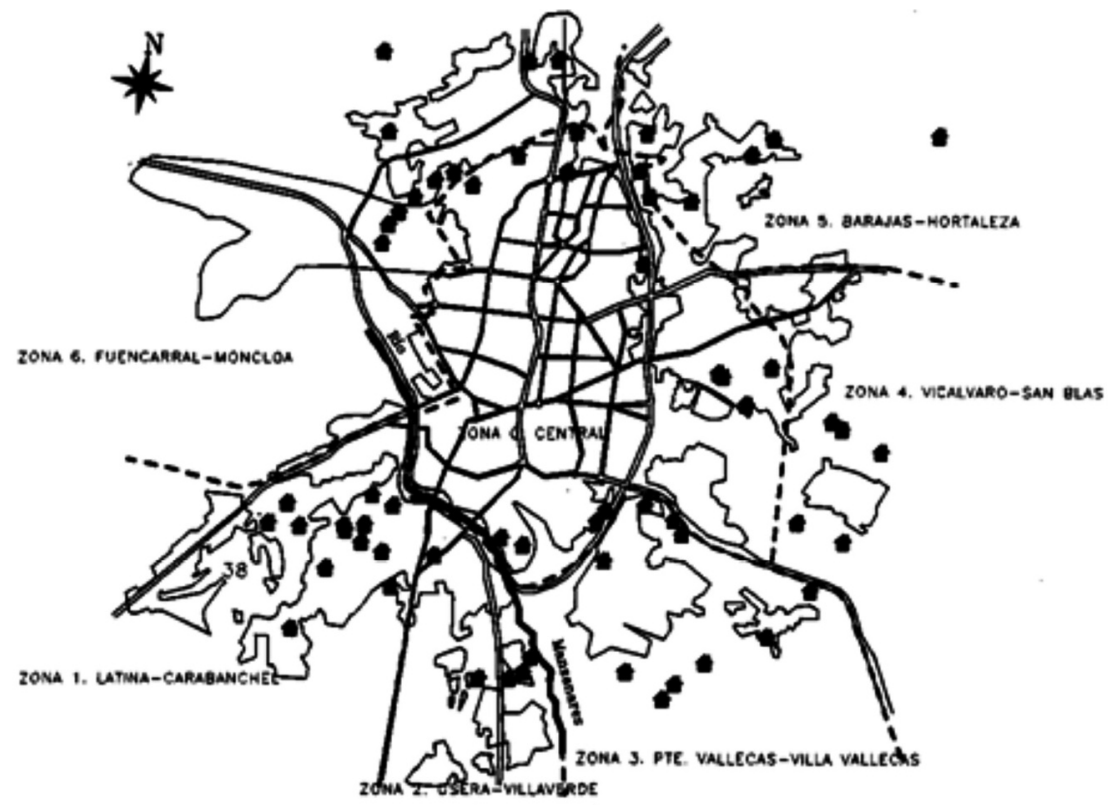

Fuente: Elaboración propia a partir de los datos de las memorias del Consorcio.

zaron los problemas. El Estado Central decidió no realizar aportaciones económicas, sólo respetó el hecho de que las viviendas prefabricadas serían aportadas por el MOPU. El Estado dejó de pagar las cantidades comprometidas argumentando la trasferencia de competencias en materia de vivienda a las Comunidades Autónomas. Su excusa para retirarse económicamente del proyecto era que el Ayuntamiento y la Comunidad debían asumir sus responsabilidades en programas y proyectos que eran ya exclusivamente de su competencia.

Tras el primer convenio, Ayuntamiento y Comunidad, creyeron que el MOPU, tal como ya lo hizo en las actuaciones del Programa de Barrios en Remodelación de 1979, iba a hacerse cargo financieramente de parte de los realojamientos. Pero finalmente, Ayuntamiento y Comunidad se vieron forzadas a elevar sus aportaciones de capital al proyecto a 25 millones de pesetas anuales cada una para compensar los impagos del Estado Central. 
El Consorcio al no disponer de suficientes fondos para continuar actuando ralentizó los realojos, especialmente a partir de 1991, provocando la primera crisis del organismo y la paralización de sus actividades entre 1991 y 1995. La falta de apoyo presupuestario desencadeno en 1993 un expediente de regulación de empleo que supuso el despido de un tercio de la plantilla e importantes enfrentamientos entre Ayuntamiento y Comunidad de Madrid. La desconfianza mutua generó un desfase presupuestario de 250 millones de pesetas (entre 1991 y 1995) ya que ninguna de ellas aportaba las cantidades comprometidas al desconfiar de la otra.

La escasez de ingresos paralizó los realojos y generó la frustración de los afectados. Los programas sociales de apoyo a la inserción residencial se redujeron hasta casi su desaparición y comenzaron los problemas de delincuencia asociados a la venta de drogas, tanto en los poblados de transición, como en los núcleos de chabolas. Aparecen los denominados «supermercados de la droga» y empiezan las movilizaciones vecinales de las barriadas limítrofes que reclamaban el desmantelamiento de los poblados chabolistas y de los núcleos de realojamiento transitorio o su traslado a otras zonas alejadas del entorno urbano. El conflicto estalla en Villaverde.

En 1991, el 8 de octubre, la Federación Regional de Asociaciones de Vecinos, con el apoyo de la Unión General de Trabajadores y de Comisiones Obreras, ante esta complicada situación presenta un Plan Complementario para intentar buscar soluciones y posibilitar la continuidad de los realojamientos. El Plan insistía sobre todo en la necesidad de colaboración entre entidades públicas y en el desarrollo de políticas de intervención transversal. El Plan finalmente no fue tomado en consideración por ninguna de las administraciones implicadas.

En un esfuerzo por intentar solucionar la parálisis que sufría el Consorcio en 1993 se redacta, por parte de la Comunidad de Madrid, con el beneplácito del Ayuntamiento, el Plan de Erradicación Urgente del Chabolismo en Madrid con el que se pretendía realojar a 618 familias en viviendas en altura y a 537 en viviendas de tipología especial.

Gracias a este nuevo impulso, entre 1993-1994, el Consorcio se realojó a 594 familias y entre 1994-1995 a otras 561.

La necesidad de aunar fuerzas en la lucha contra el chabolismo permitió que tanto el Ayuntamiento, a través de la Empresas Municipal de la Vivienda y Suelo como a la Comunidad, a través del IVIMA, aportaran nuevas viviendas. Cada una tramitaría los expedientes relacionados con sus propias adjudicaciones. Además, ambas se comprometían a aportar dinero en situaciones especiales de impago de alquileres por parte de las familias realojadas (al menos durante dos años). 
Las aportaciones de viviendas para este Plan, en el caso de la Comunidad de Madrid, se realizaron a través de la Dirección General de la Vivienda (DGAV) y el Instituto de la Vivienda de Madrid (IVIMA). La Comunidad se comprometía a aportar 996 pisos, 95 viviendas de tipología especial prefabricada y 242 casas bajas con patio trasero consideradas también provisionales. El Ayuntamiento, por su parte colaboraría a través de la Empresa de la Vivienda y el Suelo (EMV) y facilitaría 549 pisos, 372 viviendas de tipología especial prefabricada y 83 casas bajas con patio trasero.

Las presiones de Ayuntamiento y Comunidad sobre el Estado Central obligaron finalmente a que éste también se implicará, a través del Ministerio de Obras Públicas y Urbanismo, aportando puntualmente hasta un total de 57 pisos y facilitando la adquisición en el mercado de segunda mano de 262 viviendas.

Se construyeron en total cuatro barriadas de unifamiliares con patio trasero: las de Plata y Castañar, La Celsa, La Rosilla y la Quita. Además se levantaron cinco barriadas de prefabricados: las de Cañaveral, Liebres, San Fermín, Jauja y Mimbreras, cuyo tipo de edificación era muy precaria como se pueden ver en las Fotos 1, 2 y 3 . Todas ellas se encontraban alejadas del entorno urbano, para evitar la conflictividad con las comunidades de vecinos próximas, pero la propia lejanía de los núcleos acabaron por convertirlos en guetos.

Fото 1

\section{UNIDAD DE REALOJAMIENTO TRANSITORIO EN VIVIENDAS PREFABRICADAS DE LAS LIBRES, DISTRITO DE FUENCARRAL-EL PARDO}

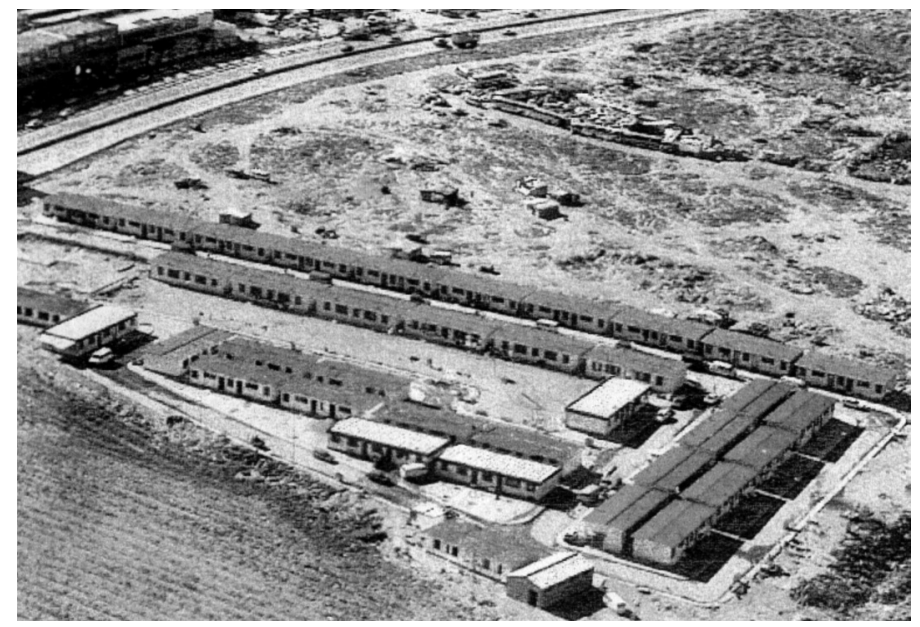

Fuente: Memorias del Consorcio. 
FoTо 2

BARRIADA DE PREFABRICADOS DE JAUJA

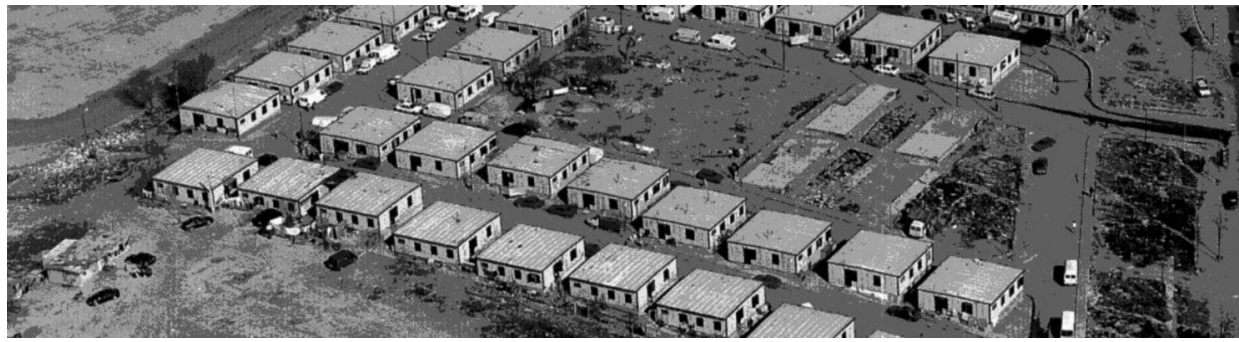

Fuente: Memorias del Consorcio.

Foto 3

BARRIADAS DE VIVIENDAS UNIFAMILIARES CON PATIO DE PLATA Y CASTAÑAR

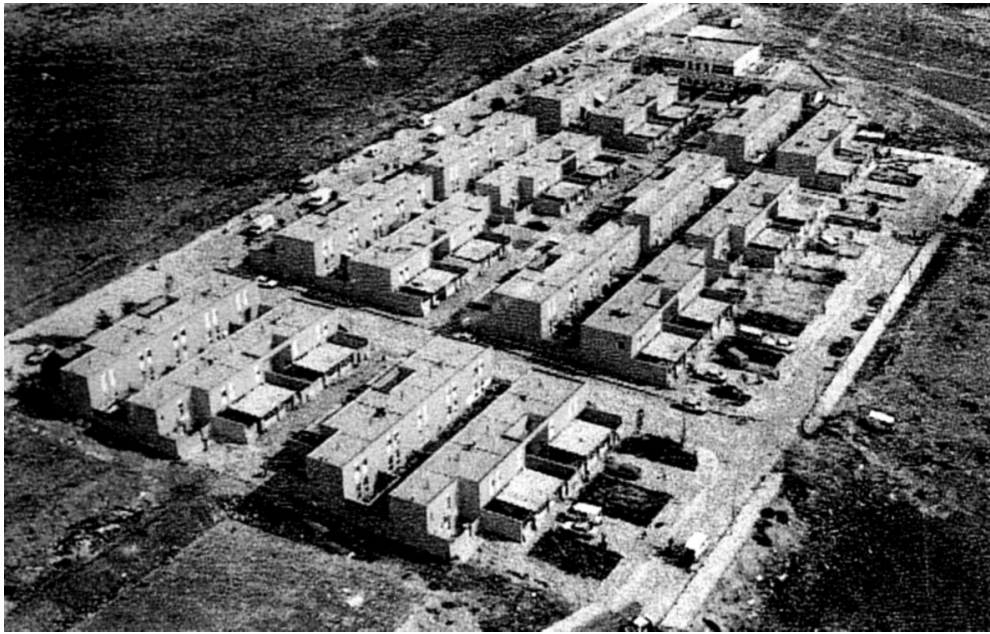

Fuente: Memorias del Consorcio.

A pesar de todos los esfuerzos de cooperación entre administraciones estos no supusieron que el chabolismo dejará de crecer en Madrid y en 1994 se planteó la necesidad de elaborar una Ley de Erradicación del Chabolismo de la capital en la que se determinaran con exactitud las funciones y responsabilidades de cada uno de los entes públicos para ser más eficientes y evitar futuros problemas. 
El Ayuntamiento tenía muy clara la importancia de dicha ley que facilitaría sus actuaciones, sobre todo teniendo en cuenta las necesidades de crecimiento de la ciudad que se estaba viendo comprometida por la presencia de los núcleos de chabolas. Así lo puso de manifiesto el informe de noviembre de 1994 de la Gerencia Municipal de Urbanismo en él que se señalaba la necesidad de eliminar estos asentamientos para poder continuar con el crecimiento de la ciudad, tal como había sucedido tan sólo unos años atrás con el anterior Plan General de Ordenación Urbana de 1985.

La existencia de dichos espacios de marginalidad afectaban en estos años al desarrollo del Plan General de Ordenación Urbana (PGOU de 1995). Las chabolas ocupaban 5.223.567 metros cuadrados de suelo necesario para la ciudad $\left(774.021 \mathrm{~m}^{2}\right.$ para zonas verdes; $2.730 .357 \mathrm{~m}^{2}$ para uso residencial; $179,558 \mathrm{~m}^{2}$ para uso industrial; $288.166 \mathrm{~m}^{2}$ para uso educativo y cultural; 858.894 para uso deportivo y 392.571 para uso rotacional. Ver Noguez Saez, 2010, p. 227.

Ese mismo año, 1994, la Gerencia del Consorcio elabora un nuevo censo de chabolas que pone de manifiesto que a pesar del enorme esfuerzo realizado y del duro trabajo de los años anteriores (ver figura 4) aún quedaban por eliminar 1.031 chabolas de las censadas en 1986 y además habían surgido 640 nuevas autoconstrucciones consideradas ilegales, asentadas en antiguos núcleos, fruto del crecimiento vegetativo de su población. Otras 462 chabolas se habían levantado en nuevos asentamientos. La realidad de este censo evidenciaba la cronicidad del fenómeno.

Entre 1994 y 1996 se intentó dar un nuevo impulso al proyecto y en sólo dos años se consigue realojar al $71 \%$ de las familias que quedaban pendientes de las originariamente censadas en 1986. Pero el nuevo censo mostró que en paralelo existían 1.026 nuevas chabolas en la capital, surgidas en los últimos diez años. El chabolismo no dejaba de crecer y era necesario establecer un nuevo plan de realojamientos (Plan de Realojamientos 1996-1999).

El nuevo Plan de Realojamientos propicio continuos y numerosos desencuentros entre Ayuntamiento y Comunidad. Sólo quedaban 66 familias $^{2}$, del censo oficial de 1986, por ser realojadas pero las disputas entre administraciones eran continuas. Los desencuentro provocaron que coincidiendo con los últimos traslados de familias en 1998 se diera por concluida la actividad del Consorcio. Su desaparición no significó que el problema se hubiera resuelto, como hemos indicado anteriormente, ya que el chabolismo se había regenerado con el propio crecimiento vegetativo de los núcleos y por la llegada de poblaciones de otras zonas.

\footnotetext{
${ }^{2}$ Del total de las 66 familias restantes, 43 se localizan en el núcleo de Antonio Leyva, 2 familias en el de Rodríguez Jaén, 19 en el de Puerta de Hierro y 2 en el de Los Olivos.
} 
En 1999, la Comunidad de Madrid volvía a tener 1.550 familias chabolistas asentadas en la propia capital y en municipios cercanos. Pese a los esfuerzos llevados a cabo en los años anteriores por acabar con el fenómeno y aunque el Consorcio había realizado 4.690 demoliciones de nuevas autoconstrucciones y había realojado a 2.192 familias, el chabolismo seguía creciendo.

En 1999 fue necesaria una reformulación de todos los planteamientos anteriormente aplicados y se rediseño otro Plan de Actuaciones. Se toma la decisión de crear un nuevo organismo, el Instituto de Realojamiento e Integración Social conocido como IRIS (BOE de 6 marzo 1999, Ley 16/1998. De 27 de octubre).

\section{LA CREACIÓN DEL IRIS Y SUS ACTUACIONES}

\subsection{Los primeros años y el cambio de estrategia}

Tal como venimos señalando, los continuos esfuerzos de colaboración van seguidos de constantes desencuentros entre administraciones a lo largo del

FIGURA 5

EVOLUCIÓN DEL CHABOLISMO EN MADRID 1986-1999

Descenso del número de chabolas en Madrid entre 1986 y 1999 de las censadas por el Consorcio en 1986

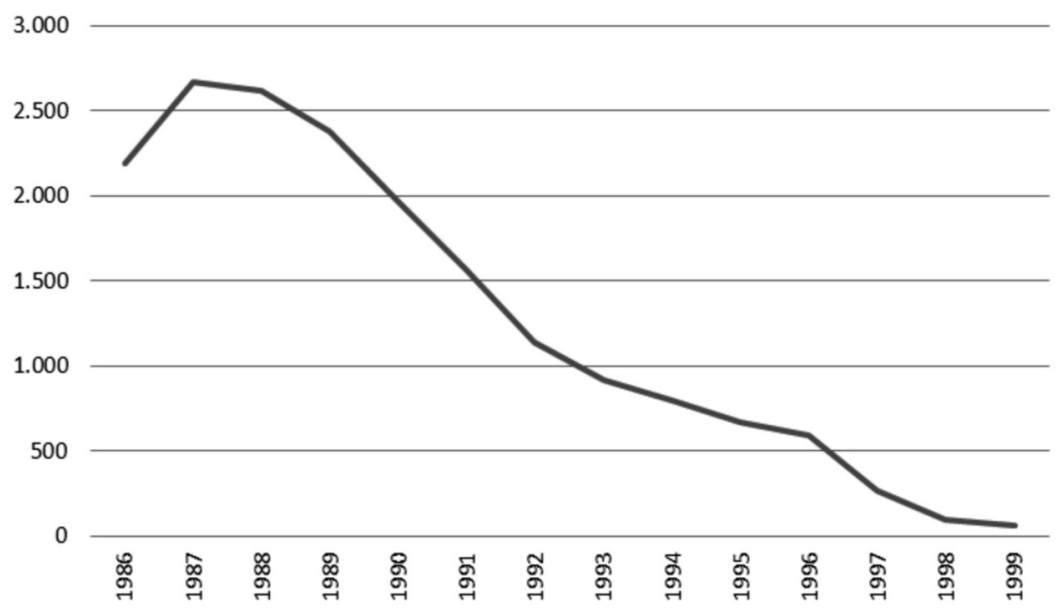

Fuente: Elaboración propia a partir de los datos de censos y memorias del Consorcio para el Realojamiento de la Población Marginada, Memoria Final de Actuaciones de 1998. Informe del IRIS 1999, documentos internos. 
periodo 1986-1998, por temas tanto financieros, como competenciales, que dificultaron y paralizaron los realojamientos.

Con la disolución del Consorcio en 1998 la Comunidad decide asumir en exclusiva las competencias en materia de realojamientos promoviendo el desarrollo legislativo y la creación de un organismo que recogiera dichas competencias. El 27 de octubre de 1988 se aprobó la Ley 16/1998, por la que se crea el Instituto de Realojamiento e Inserción - IRIS. En el capítulo I de la citada Ley se indicaba que el IRIS se creaba adscrito a la Consejería de Obras Públicas, Urbanismo y transportes de la Comunidad de Madrid. La finalidad de organismo era ayudar a los Ayuntamientos de la Comunidad Autónoma a resolver los problemas de realojamientos y eliminación de autoconstrucciones existente en sus territorios, ya que la gran mayoría de ellos no contaban con experiencia suficiente en esta materia, ni tenían capacidad para hacerse cargo de un fenómeno que les sobrepasa.

Los Ayuntamientos no disponían, ni de los recursos económicos necesarios para proporcionar una vivienda digna a los afectados, ni de la experiencia técnica para su integración social y laboral ${ }^{3}$. El IRIS pretendía encargarse de las necesidades de ésta población, tanto de su derecho a una vivienda, como de su apoyo asistencial, con el objetivo de su integración social y laboral. De hecho, su denominación ya aludía a dichas responsabilidades al crearse como Instituto de Realojamiento e Integración Social, haciendo clara referencia a sus funciones.

Con la creación del IRIS, la Comunidad intentaba volver a propiciar la colaboración tanto con la Administración Central del Estado (a través del Ministerio de Fomento, Ministerio de Trabajo y Asuntos Sociales), como con los Ayuntamientos de su territorio. Así como la coordinación de actuaciones con otras Comunidades limítrofes. Se hizo un gran hincapié en que la necesaria participación en entidades públicas de diferentes ámbitos competenciales para su buen funcionamiento.

La primera actuación del organismo fue la realización de un nuevo censo de chabolas tanto de la capital como de los demás municipios de la Comunidad. El recuento mostró que en la ciudad de Madrid aún quedaban 1.550 familias por ser realojadas, localizadas en 14 distritos, figura 6 . Y el problema se extendía a otros 15 municipios donde existían 305 chabolas, figura 7.

\footnotetext{
${ }^{3}$ Aunque no se especificó nunca en la ley hasta qué punto los ayuntamientos eran responsables de este proceso y cuantas viviendas aportarían cada uno de ellos para llevar a cabo dichos realojamientos.
} 
FIGURA 6

NÚMERO DE CHABOLAS POR DISTRITO EN MADRID SEGÚN EL CENSO DEL IRIS DE 1998

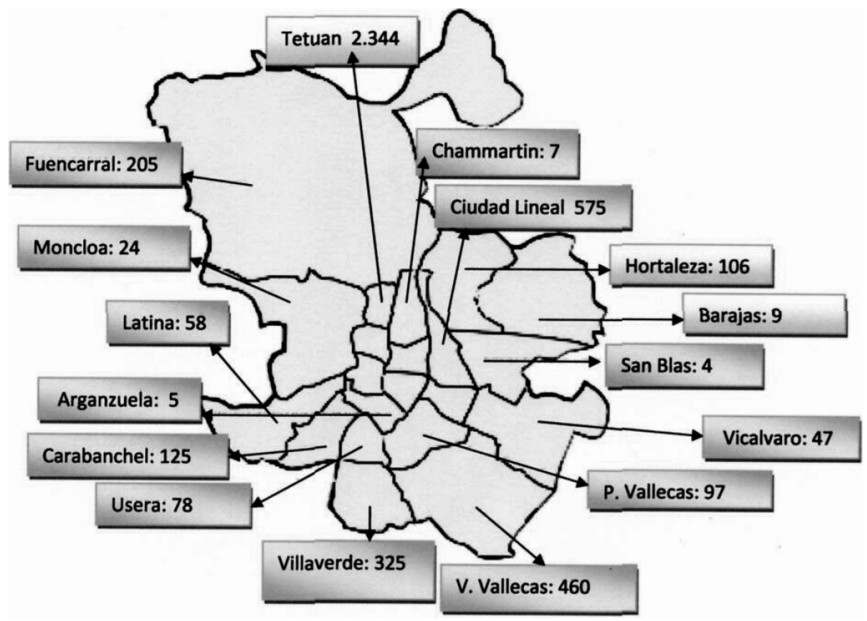

Fuente: Elaboración propia a partir de las memorias del IRIS.

FIGURA 7

NÚMERO DE CHABOLAS POR MUNICIPIO EN LA COMUNIDAD DE MADRID SEGÚN EL CENSO DEL IRIS DE 1998

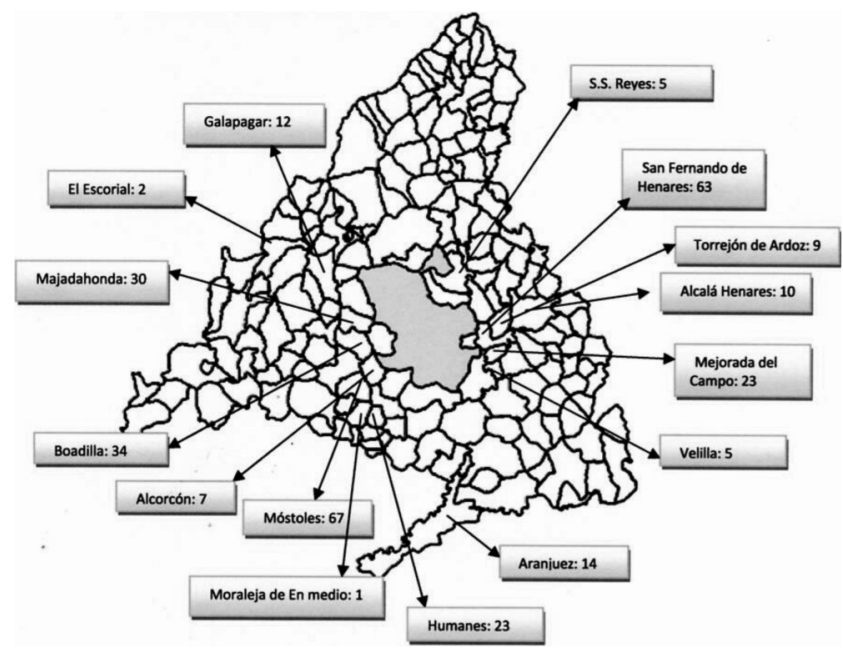

Fuente: Elaboración propia a partir de las memorias del IRIS.

Estudios Geográficos, Vol. LXXV, 276, pp. 219-260, enero-junio 2014

ISSN: 0014-1496, eISSN: 1988-8546, doi: 10.3989/estgeogr.201406 
La atribución de personalidad jurídica al IRIS fue imprescindible para su funcionamiento y para la coordinación de los recursos necesarios encaminados a eliminar el chabolismo. En comparación con la etapa anterior del Consorcio se produjo un cambio en la estrategia de gestión, con una única dirección y un único gerente del organismo (a diferencia de lo que había sucedido en el Consorcio), lo cual mejoró y facilitó sus actuaciones ${ }^{4}$. El IRIS se hizo cargo de la plantilla de trabajadores del Consorcio y sólo reemplazó a los cargos directivos.

El IRIS va a imponer determinados cambios fundamentales en este nuevo proceso de realojamientos que le diferenciarán de la etapa anterior:

- Se establecía que todas las familias en situación de exclusión social viviendo en chabolas eran beneficiarias de una vivienda digna sin necesidad de estar incluidas en ningún censo a diferencia de lo que sucedió en la etapa anterior.

- Para evitar el surgimiento de nuevas chabolas, fenómeno que se estaba produciendo debido a la constitución de nuevos matrimonios a edades muy tempranas (matrimonios concertados para conseguir una vivienda de realojamiento) se dispuso que no se permitirá ningún desdoblamiento de familias a ningún individuo que no fuera mayor de edad. Y se controlaron muy de cerca el surgimiento de nuevas chabolas a través de un organismo denominado SIVIRIS (Servicio de Apoyo para el Control del Chabolismo, hoy ya desaparecido).

- El ámbito de actuación deja de ser exclusivamente el Ayuntamiento de Madrid para ampliarse a todo el territorio de la Comunidad ${ }^{5}$ y a aquellos municipios que solicitaran ayuda.

- Se eliminó la posibilidad de cambiar de vivienda, salvo en situaciones muy especiales, no se podía renunciar a la vivienda asignada.

- Se aprobó la posibilidad de compra la vivienda adjudicada por parte de aquellas familias que lo solicitaban y socialmente demostraran estar integradas.

- Se fomentarían nuevos programas de integración social y laboral, haciendo especial hincapié en aquellos relacionados con la integración económica de los afectados. El proceso de integración social comenzaba en el poblado de chabolas (atendiendo la escolarización, la formación de adultos, la sanidad, etc.) y seguía con el traslado a una vivienda normali-

${ }^{4}$ El primer Gerente del IRIS fue Florencio Martín Tejedor que había sido Director del Área Social del Consorcio desde 1995.

${ }^{5}$ Se establecía que las posibilidades de realojamiento deberían ser iguales para todas las familias con independencia del tamaño del Ayuntamiento en donde residieran. 
zada. El apoyo social se concretaba en diversos programas de alfabetización, empleo y escolarización. Para el control real de la efectividad de las medidas adoptadas se realizarían evaluaciones externas sobre los programas de integración social y laboral de las familias realojadas (se llevaron a cabo dos auditorias externas una en el año 2000 y otra en el 2006).

- La premisa fundamental en las actuaciones del IRIS iba a ser realojar a las familias dispersas en distintos barrios de Madrid y en otros municipios de la región, evitar su concentración y la creación de guetos. En ningún caso el IRIS permitiría que se realojase a más de una familia por bloque de viviendas.

- Otra de las grandes diferencias con la etapa anterior iba a ser que muchas de las viviendas de realojamiento iban a pisos adquiridos en el mercado inmobiliario de segunda mano. Se eliminaban además totalmente la posibilidad de realojamientos en barriadas de tipología especial.

- Posteriormente y a partir del año 2008 se crearía el ASIVECAM (Asistencia Vecinal de la Comunidad de Madrid) para mediar con las comunidades de vecinos dónde se realizaban los realojos, con un seguimiento de los procesos de integración en entornos no gitanos.

- Se hace especial hincapié en el seguimiento de apoyo escolar y laboral a las familias, incluso desde antes de los realojos.

En definitiva se trataba de un cambio completo de planteamiento tanto en cuanto a la intervención residencial como a la de carácter social e integrador.

\subsection{La colaboración del IRIS con los Ayuntamientos de la Comunidad de Madrid y los Programa-Convenio}

La Ley de constitución del IRIS ${ }^{6}$ justificaba todos los puntos anteriores indicados insistiendo en la permanencia y regeneración continua del chabolismo que se llega a clasificar como «fenómeno crónico» en la Comunidad. La Ley establecía la actividad del Instituto que se llevaría a cabo a través del desarrollo de Programas-Convenio de carácter contractual con las administraciones municipales, estableciéndose los servicios que estos debían prestar, y los requisitos que debían cumplir los beneficiarios de los realojos.

La figura del Programa-Convenio se establecía como un instrumento de colaboración con las entidades municipales. Para entender esta figura legal es

\footnotetext{
${ }^{6}$ Ley 16/1998, de 27 de octubre, de Creación del Instituto de Realojamiento e Integración Social. BOCM 30 de octubre de 1998, BOCM 16 de diciembre de 1998.
} 
necesario comprender que extinguido el Consorcio en 1998 se realizó un reparto de responsabilidades en materia de realojamiento entre la Comunidad de Madrid y el Ayuntamiento de la capital y dicho reparto supuso el inicio de una nueva etapa en la que el IRIS era el protagonista y los agentes implicados eran todos los municipios de la Comunidad, incluido él de la capital.

Los Ayuntamientos interesados firmarían Programa-Convenio de colaboración con el IRIS y el IRIS se comprometía a realojar a sus chabolistas. En el caso concreto de la ciudad de Madrid, el IRIS además se ocuparía de atender y realojar a las familias de las antiguas Unidades de Realojamiento Especial. La firma de estos Programas-Convenios suponía la continuidad, pero también la mejora, de la estrategia de trabajo llevada a cabo por el Consorcio.

En la búsqueda de una mayor colaboración y un mejor entendimiento, el 10 de mayo de 1999, se llegó a un acuerdo con la Federación Madrileña de Municipios que se concretó en la firma de un documento, en julio del mismo año, que vinculaba a todos los alcaldes de la Comunidad en la lucha contra la marginalidad residencial. En base a este acuerdo se comprometían a admitir en sus territorios a familias chabolistas procedentes de otras zonas cuyo número sería proporcional al de su población censada y nunca podría suponer más de un 5\% de la misma. Se tendría muy en cuenta la presencia de familias gitanas de realojos anteriores en la zona. En aquellos Ayuntamientos donde hubiera una alta concentración previa de realojados se llevarían a cabo proyectos de desarrollo comunitario que facilitaran la integración de las familias con los vecinos.

Los alcaldes garantizaron además que velarían por evitar el surgimiento de guetos y el crecimiento de nuevos núcleos de chabolas. También se comprometieron a llevar a cabo una mayor intervención social con los afectados de forma coordinada con los trabajadores del IRIS. El IRIS se convirtió en el canal de colaboración necesario entre Ayuntamientos y Comunidad Autónoma. Era el organismo de la Comunidad de Madrid dedicado a erradicar el chabolismo y la infravivienda por antonomasia

El IRIS mantuvo mejores relaciones con municipios como Alcorcón, Móstoles, Rivas Vaciamadrid o Getafe que con el de la capital. Dichos municipios le permitieron repartir por sus territorios a un importante porcentaje de chabolistas procedentes de distintos núcleos. Ayuntamiento y Comunidad mantenían posturas enfrentadas sobre como se debía gestionar la política de realojamientos. En especial con respecto a los antiguos barrios de prefabricados y vivienda unifamiliares. Los desencuentros fueron continuos en particular con intervenciones como las llevadas cabo en barrios como Plata y Castañar o Mimbreras. 
A través del IRIS se firmaron 32 Programas-Convenios con Ayuntamientos de la Comunidad para el desarrollo de intervenciones de realojamiento. El protocolo de actuación era igual en cada uno de los casos. Se establecía que cuando comenzará la intervención sobre un determinado núcleo de chabolas las familias afectadas debían rellenar una solicitud de realojo que sería estudiada y tramitada por el IRIS. El personal del IRIS con suficiente experiencia y capacitación ayudaría al personal de los Ayuntamientos a evaluar cuantas de dichas familias cumplían los requisitos para ser incluidas en los programas de realojamiento. Cuando una solicitud era admitida a trámite la familia chabolista firmaría un contrato de arrendamiento de la nueva vivienda que conllevaría una serie de cláusulas sociales. Inmediatamente, tras ser realojadas y ocupar su nueva vivienda, la chabola debía ser derribada para evitar su reocupación y la aparición de nuevas chabolas en la zona.

Con la llegada de la familia a la nueva vivienda los asistentes sociales del IRIS harían de mediadores sociales con el presidente de su comunidad de vecinos y les informarían sobre todas sus obligaciones incluidas el pago de los gatos necesarios en la comunidad. Así mismo, les informaría, tanto a ellos, como a la comunidad de vecinos, del seguimiento continuo y periódico por parte de dichos asistentes sociales de las familias realojadas. El acompañamiento de los afectados duraría hasta que se normalizarán sus relaciones de convivencia con la comunidad y se acostumbraran al uso de los sistemas públicos de protección social (salud, educación, servicios sociales).Dicho seguimiento se mantendría el tiempo necesario que requiera cada familia en función de sus circunstancias ${ }^{7}$.

Todos los Programas-Convenio debían funcionar de forma similar. Los recursos económicos procederían de los presupuestos de la CAM y las líneas de actuación (tal cómo se recoge en el artículo 4 de la Ley de su creación) se centrarían en:

1.- Proporcionar viviendas a familias chabolistas en riesgo de exclusión a través de viviendas de segunda mano adquiridas en el mercado o bien viviendas sociales ${ }^{8}$. El IRIS priorizaría claramente en sus actuaciones

\footnotetext{
${ }^{7}$ Días después de efectuado el realojo se reúnen los asistentes sociales y afectados para recordar y aclarar los derechos y deberes de ellos y de sus vecinos. El IRIS elabora material pedagógico adaptado para las familias que van a ser realojadas con instrucciones básicas para el uso de la nueva vivienda, así como normas de convivencia en el vecindario a través de dibujos e imágenes de fácil comprensión.

${ }^{8}$ La CAM destina sólo el $10 \%$ de la vivienda social que construye a población chabolista para evitar su concentración.
} 
las viviendas en altura y rechazaría los barrios de tipología especial, lo que suponía una gran diferencia con la etapa anterior.

2.- Hacer un seguimiento de las familias realojadas para evitar el uso fraudulento e inadecuado de las viviendas adjudicadas y mejorar la convivencia con los vecinos.

3.- Facilitar la integración social de las familias incluidas en programas de realojamiento. El trabajo se concentraría tanto a las residentes en chabolas, infraviviendas o en barrios de tipología especial de etapas anteriores, como en aquellas alojadas en vivienda normalizadas, siempre que siguieran necesitando de la intervención social. Dicha intervención se llevaría a cabo a través de Unidades de Trabajo Social en poblados y asentamientos y se coordinaba con otras entidades públicas, como los Servicios Sociales de cada municipio. Las actuaciones comenzarían mucho antes de la adjudicación de una vivienda, en los propios núcleos chabolistas, a través de programas de alfabetización, formación laboral, escolarización infantil, sanidad, etc.

4.- Realizar un control y seguimiento del chabolismo en la región para lograr una distribución territorial de los realojos lo más equitativamente posible, entre todos los municipios implicados y evitar la formación de guetos.

En definitiva aunque pueda considerarse una política de continuación con la etapa anterior del Consorcio se llevaron a cabo grandes cambios en su estrategia de actuación.

\subsection{El Consorcio y el IRIS: veinte años de éxitos y fracasos en la lucha contra el chabolismo}

A pesar de todas las críticas que se puedan realizar al respecto las intervenciones del Consorcio y del IRIS es necesario reconocer que las actuaciones llevadas a cabo por ambos organismo, a lo largo de los últimos veinte años, han permitido desmantelar 6.012 chabolas y atender a 27.000 personas, con políticas de intervención social y apoyo (en el ámbito social, psicológico, pedagógico, laboral y sanitario, etc.). La eficacia de todas estas medidas hubiera sido nula si no se hubieran basado en políticas de actuación trasversal en colaboración siempre con otros organismos públicos necesarios de las distintas administraciones.

Sólo cuando se hace posible esta colaboración entre entidades se pueden obtener resultados como que el $96 \%$ de todas las familias realojadas se han integrado con éxito en la sociedad o que se han conseguido que el $100 \%$ de los 
niños de estos enclaves hayan sido escolarizados. Los programas laborales han logrado un total de 2.000 empleos por cuenta ajena para la población afectada. Y entre los años 1999 y 2010 el IRIS ha desmantelado 60 núcleos chabolistas y ha proporcionado una vivienda digna a 1.700 familias.

Entre las intervenciones una de las más complejas ha sido, sin duda, el desmantelamiento de las Unidades Especiales de Realojamiento conocidas como Barrios de Tipología Especial de la etapa anterior del Consorcio. Como ya indicamos en puntos anteriores, la disparidad de criterios entre Ayuntamiento y Comunidad en la forma en que se tenían que ir desmantelando las barriadas dio lugar a infinidad de conflictos. Las nueve Unidades Especiales tenían sólo que haber sido una situación transitoria para sus moradores pero se perpetuaron, como muestra el cuadro 1, en algunos casos hasta los 20 años. Los núcleos se localizaban fundamentalmente en la zona sur-este de la capital, como muestra la figura 8 , en un entorno ya de por si degradado.

Barrios de tipología especial cómo el de Las Mimbreras (Latina), por ejemplo, ha sido uno de los últimos en desaparecer y ello gracias a la intervención del IRIS que supuso la firma de un convenio de colaboración entre la Comunidad y el Ayuntamiento de Madrid en 2008 para su desmantelamiento, con el

\section{CuAdro 1}

EVOLUCIÓN DE LAS UNIDADES ESPECIALES DE REALOJAMIENTO 1986-2009

\begin{tabular}{llccc}
\hline \multicolumn{1}{c}{ Distrito } & \multicolumn{1}{c}{$\begin{array}{c}\text { Nombre de } \\
\text { la Unidad }\end{array}$} & $\begin{array}{c}\text { Fecha de } \\
\text { ocupación }\end{array}$ & $\begin{array}{c}\text { Fecha de } \\
\text { desaparición }\end{array}$ & $\begin{array}{c}\text { Años de } \\
\text { ocupación }\end{array}$ \\
\hline Fuencarral & La Quinta & 1992 & 2006 & 14 \\
& Las Liebres & 1989 & 2003 & 14 \\
Latina & Jauja & 1991 & 1999 & 8 \\
Puente de Vallecas & Las Mimbreras & 1995 & 2009 & 14 \\
Usera & La Celsa & 1992 & 2000 & 8 \\
Vicalvaro & San Fermín & 1990 & 1998 & 8 \\
Villa de Vallecas & El Cañaveral & 1986 & 2006 & 20 \\
Villaverde & La Rosilla & 1992 & 2000 & 8 \\
\hline
\end{tabular}

Fuente: Elaboración propia. Memorias del Consorcio 1986-1998. Informes anuales del IRIS 1999-2011, documentos internos. 
apoyo de la EMV. Debido a este acuerdo también se desmantelaron núcleos como El Cañaveral (Vicálvaro), El Ventorrro y Santa Catalina (en el distrito de Puente de Vallecas) en los que residían 499 familias. Dichas intervenciones han supuesto una inversión de más de 110 millones de euros aportadas por el gobierno regional y el municipal.

FOTO 4

\section{BARRIADA DE TIPOLOGÍA ESPECIAL LAS MIMBRERAS (LATINA)}

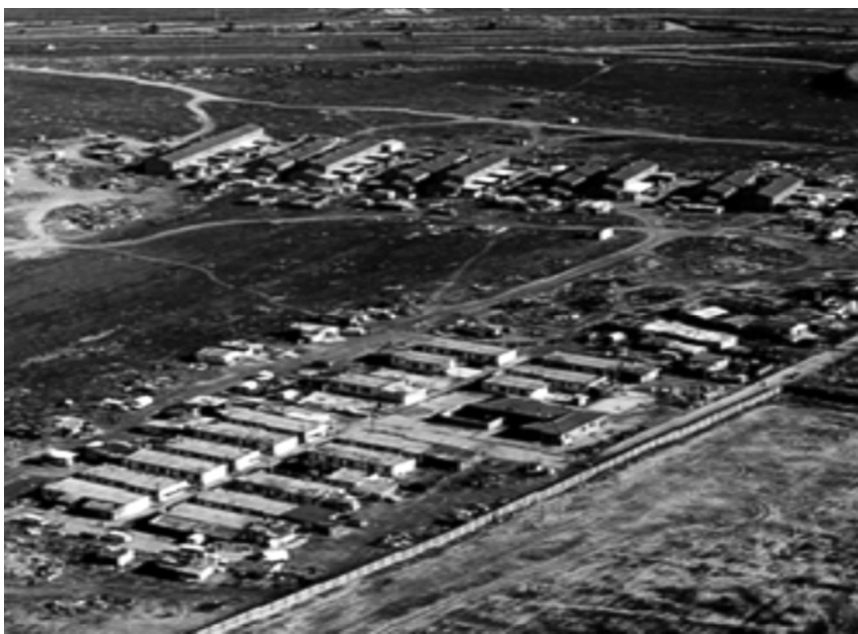

Fuente: Memoria del IRIS, 1999, p. 58.

FOTо 5

\section{BARRIADA DE EL CAÑAVERAL (VICÁLVARO)}

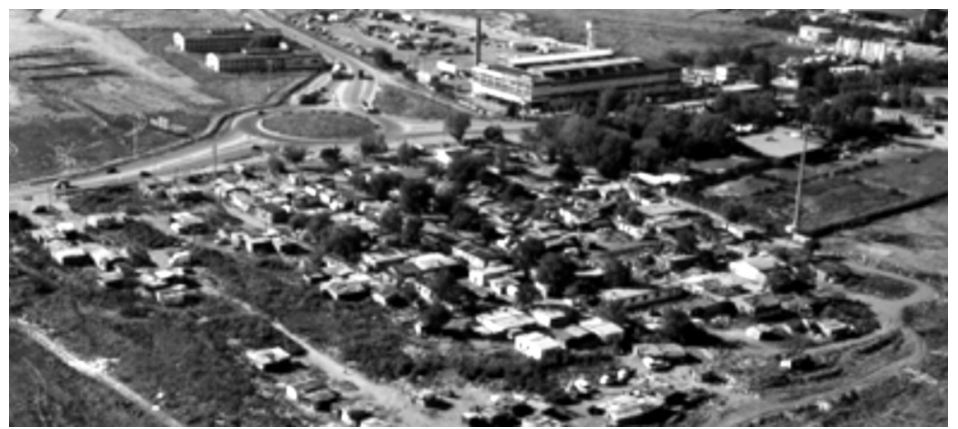

Fuente: Memoria del IRIS, 2008. 
Es necesario reconocer que el interés en el desmantelamiento de estos núcleos no ha sido un hecho altruista sino que volvió a ser, cómo en la época del Consorcio, necesario para la liberación de suelo por el crecimiento de la ciudad y la ejecución del actual Plan General de Ordenación Urbana. Los terrenos ocupados por el asentamiento de Santa Catalina, por ejemplo, han supuesto una inversión de $21.780 .000 €$ y finalmente han sido destinados a zona verde con arreglo a su calificación aprobada en dicho Plan General de Ordenación Urbana. Otras actuaciones conjuntas entre el consistorio y la Comunidad se han centrado en los núcleos de El Salobral o las antiguas unidades de realojamiento de los barrios de El Cañaveral o la de Plata y Castañar, no exentos todos ellos de graves problemas sociales.

En el caso de la ciudad de Madrid, desde la recuperación del vacío de poder que supuso la creación del IRIS tras la disolución del Consorcio, se han llevado a cabo toda una serie de intervenciones realizadas, bien de forma individual por el consistorio de la capital o bien de manera conjunta con la Comunidad, que han supuesto entre el año 2004 y el año 2011 un total de 2.083 derribos de chabolas, lo que representaba un porcentaje de un 132\% sobre el objetivo inicial del Ayuntamiento en 1999 que fue actuar sobre 1.575 chabolas.

Pero entre todas las intervenciones de las que se ha hecho cargo el IRIS una de las más complicadas, social y urbanísticamente, sigue siendo la de la Cañada Real Galiana de Valdemingómez que afecta a varios municipios ${ }^{9}$ y que ejemplifica la dificultad de este tipo de intervenciones. La disparidad de criterios entre organismos públicos implicados y la lucha competencial ${ }^{10}$ esta ralentizando cualquier decisión sobre esta zona.

\section{LAS ACTUACIONES DEL IRIS: UN MODELO DE CAMBIO}

\subsection{Las Viviendas de Integración social: una oportunidad de actuación}

Con la firma del Plan de Vivienda 1997-2000 de la Comunidad de Madrid se incorporará la figura de las Viviendas de Integración Social (VIS). La aprobación y creación de dicha modalidad residencial por parte de la Dirección

${ }^{9}$ El poblado de chabolas la Cañada Real se extiende a lo largo de 15 kilómetros desde la Avenida de la Cañada en Coslada hasta el límite municipal de Madrid y Getafe, atravesando los términos municipales de Coslada, Rivas-Vaciamadrid y Madrid.

10 También sería destacable la intervención y el programa-convenio que se firmó con el Ayuntamiento de Getafe. 
General de la Vivienda se logró gracias al Decreto 43/97, de 13 marzo. Las Viviendas de Integración Social han sido la base de actuación de los convenios suscritos por el IRIS con los distintos Ayuntamientos y han permitido que cientos de familias de etnia gitana abandonaran sus chabolas.

Se trata de viviendas dirigidas a personas necesitadas de protección social. Con anterioridad a la creación de dicho modelo residencial muchas familias chabolistas fueron llevadas a alojamientos prefabricados o de unifamiliares en barriadas de tipología especial que, como ya hemos indicado anteriormente, dieron lugar a auténticos guetos. El IRIS abandonará completamente esta formula residencial y optará por viviendas en altura, repartidas por toda la ciudad, dentro de comunidades de vecinos amplias y no gitanas. Se trataba de alojamientos concebidos con una gran flexibilidad en cuanto a su localización y su tamaño que se adaptaban a los convenios que iba firmando entre el IRIS con los distintos ayuntamientos de la Comunidad.

Los objetivos de las intervenciones del IRIS a partir de estos programas de viviendas eran:

- Facilitar a las familias un hogar con las instalaciones específicas, que les permitieran una mejora en su calidad de vida, en edificios y barrios dotados de equipamientos que cubrieran sus necesidades.

- Las viviendas debían localizase en entornos con disponibilidad de instalaciones complementarias para la capacitación y formación de los afectados.

- Se suscribirían convenios con los organismos encargados del proceso de realojamiento en cada Ayuntamiento y si fuera necesario se anticiparían las subvenciones al inicio de las obras.

- Se realizaría un seguimiento efectivo de evolución de las familias y se las apoyaría y ayudaría de forma continuada hasta su adaptación.

El desarrollo de esta modalidad edificatoria fue posible, a partir de 1999, gracias a la firma de sucesivos convenios de colaboración entre el IRIS y la Consejería de Obras Públicas, Urbanismo y Transporte de la Comunidad de Madrid. El primero de todos ellos fue para la adquisición de 150 viviendas anuales al amparo del Plan de Vivienda de la Comunidad de Madrid 19972000. A este le siguió un segundo convenio para la adquisición de 320 viviendas y un tercero en el año 2001 (Decreto 11/2001) para la compra de 500 viviendas dentro del Plan de Vivienda de la Comunidad de Madrid 2001-2004 y así sucesivamente.

Las características de todas estas viviendas eran muy similares: debían tener una superficie construida máxima de 100 metros cuadrados y excepcionalmente 
de 130 metros cuadrados para familias numerosas de entre siete y diez miembros. El acceso a las viviendas se hacía a partir de préstamos o subvenciones ${ }^{11}$.

Todas las viviendas iban destinadas a familias carentes de alojamiento con graves problemas de exclusión social. Todas ellas presentaban, según la Dirección General de Urbanismo, una grave situación de exclusión. Menos de un $30 \%$ de las mismas disponía de DNI; únicamente el $42 \%$ de los niños estaban escolarizados; mantenían comportamientos demográficos atrasados con un ratio de 5,1 miembros por familia y índice de analfabetismo que superaba el $70 \%$ incluso entre la población joven y especialmente altos entre las mujeres.

El proceso de realojamiento de los afectados empezaba mucho antes de la adjudicación de una vivienda, incluso varios años antes. El IRIS trabajaba con las familias de forma transversal (con programas de alfabetización, escolarización, integración y costumbres, hábitos sanitarios y de comportamiento, formación laboral, etc.). Realizada la solicitud de vivienda por parte de la familia se le habría un expediente y se estudiaba su situación. Si cumplía con los requisitos para ser incorporada al programa se comenzaba a trabajar con ella. El estadio final del proceso era la firma del contrato de arrendamiento de la vivienda, que siempre incluía cláusulas sociales, y su adjudicación.

Se intentaba que la vivienda se localizara en la zona elegida por la familia, que solía coincidir con aquella próxima a donde se encontraba su chabola y en la que la familia solía tener lazos familiares y laborales. Realizado el realojamiento, de forma inmediata se procedía a la demolición de la chabola para evitar su reocupación. La familia era acompañada a la nueva vivienda por los asistentes sociales del IRIS, llevándose a cabo un seguimiento social de la misma hasta su integración plena en la comunidad de vecinos.

Los resultados alcanzados por el IRIS a través del programa de Viviendas de Integración Social han supuesto el realojamiento de 2.344 familias y la firma de 9 convenios de colaboración con Ayuntamientos. Se han construido

${ }^{11}$ Préstamo: Su cuantía será del 50\% del coste de construcción de las viviendas y del 100\% del coste de la construcción de las instalaciones para la integración y capacitación de sus moradores. En el supuesto de adquisición de inmueble para destinarlo a Viviendas de Integración Social, la cuantía máxima del precio será la suma del $50 \%$ de su valor de tasación, sin que dicha cuantía pueda superar el precio máximo legal de venta de las Viviendas de Protección Oficial de Régimen Especial y del 100\% del coste de las instalaciones para la integración y capacitación de sus moradores. Estos préstamos, podrán contar con una subsidiación, que oscilará entre el 30\% y el $50 \%$ de la cuota, en función del período de amortización.

Subvención: En una cuantía equivalente al 50\% del coste de construcción de las viviendas. En el caso de adquisición de inmuebles para destinarlo a VIS, la subvención alcanzará hasta el $50 \%$ del valor de tasación. 
un total de 1.768 viviendas (de entre 100 a $130 \mathrm{~m}^{2}$ ). Se ha incrementad el número de niños escolarizados pasando de un $42 \%$ en 1978 a un $98 \%$ ya en el año 2001 y un $100 \%$ en 2006 . Se ha conseguido un $100 \%$ de cobertura sanitaria pública. Se ha modificado el comportamiento demográfico de las familias con una reducción en el número de miembros por unidad familiar de 5,1 a 4,1 . Y se ha conseguido que el $100 \%$ de los afectados tengan DNI. En definitiva un gran esfuerzo con muy buenos resultados.

\subsection{La actividad del IRIS en los últimos años y su repercusión internacional}

En el año 2003 el IRIS sufre su primera crisis institucional y la consiguiente paralización de sus actividades. El paso de entonces presidente de la Comunidad de Madrid a la alcaldía de la capital implicó un cambio en las políticas de realojamiento. La indecisión del nuevo equipo de gobierno del consistorio sobre qué hacer en relación con los chabolistas y la difícil relación con la nueva presidenta de la Comunidad paralizarán las actuaciones del IRIS. En este contexto tiene lugar la dimisión de su Director Gerente en junio de 2003. El vacío de poder, hasta mayo de 2004, bloqueara la capacidad de intervención del organismo. Con el nuevo Director se recupera la actividad y se estable el compromiso de intentar realojar al menos a 100 familias chabolistas anualmente en la capital.

Los siguientes años serán complicados y de intenso trabajo. Se irán firmando diversos Programas-Convenios con diferentes ayuntamientos para el desmantelamiento tanto de núcleos chabolistas, cómo el de El Salobral, así cómo para barriadas de tipología especial, cómo la de Plata y Castañar. En marzo de 2005 se estableció la primera comisión de seguimiento de los convenios firmados entre el IRIS y Ayuntamientos como el de Madrid, y se comenzó a editar una revista de carácter trimestral sobre sus actuaciones. Se busca mejorar la imagen pública de la institución y para ejemplificar la transparencia de su gestión se retoma la publicación de sus informes anuales, para dar un mayor credibilidad. Así mismo, se firman nuevos convenios con instituciones universitarias para realizar estudios y seguimientos de sus trabajos ${ }^{12}$.

12 En el año 2005 se firma un convenio con el Instituto Madrileño de Administraciones Públicas (IMAP) y la Universidad de Granada para realizar una evaluación externa de sus actuaciones. Esta casi «auditoria» fue dirigida por el profesor de la Universidad de Granada Juan Gamella y que iba a cubrir el periodo 1999-2006. El estudio debía centrarse en el análisis de la situación de 2.114 familias realojadas en el periodo 1987-2006 incluyendo por tanto las actuaciones del Consorcio y del IRIS y se denominó: «El modelo IRIS de intervención: Su impacto en la población realojada y en la relaciones vecinales». 
Pero a pesar de todos estos esfuerzos el organismo sigue sin tener el suficiente apoyo institucional y en octubre de 2006 de nuevo se produce otro vacío de poder con el cese de su Director Gerente. Desde el nombramiento de un nuevo Director en 2006 a la actualidad el IRIS ha podido mantener una cierta estabilidad.

En el año 2008 se crea el ASIVECAM como mecanismo de intervención social para el trabajo con las mancomunidades de vecinos donde se realojaba a familias. Pieza clave de sus actuaciones y ejemplo de buenas prácticas de la institución.

Los logros obtenidos en su modelo de intervención social han llegado a ser ejemplo para otros países en el desarrollo de programas similares y se han convertido en referente internacional. Países como Croacia, Bosnia-Herzegovina o Macedonia se han interesado por este modelo de actuación. En el año 2011 el Secretario de Estado para la Inclusión Social de Hungría, Zoltan Balog, visito Madrid para conocer en persona sus actuaciones, coincidiendo con la Presidencia Europea por parte de Hungría. Los trabajos del IRIS han sido reconocidos por la Agencia Europea de Derechos Fundamentales no sólo por propiciar el cambio de alojamiento de las familias sino por propiciar su integración social.

La intervención del IRIS no solo ha sido residencial, se ha asesorado a las familias realojadas para que regularizaran su situación como ciudadanos españoles y q así obtuvieran la documentación necesaria (muchos de ellos no disponían ni de DNI). Se ha ayudado a muchos padres a conseguir becas para sus hijos en los centros escolares, pensiones para sus mayores, asistencia sanitaria para todos ellos, etc. Se ha logrado la total escolarización de los menores. Se ha dado formación profesional para la inserción laboral de los jóvenes. Se han realizado esfuerzos constantes de mediación vecinal para solucionar conflictos de ajuste de las familias realojadas con sus nuevos vecinos y su nuevo contexto en pisos de bloques, siendo especialmente intenso su trabajo con algunas familias muy problemáticas que ya habían sufrido rechazo en otras actuaciones de realojamiento. Se ha hecho un gran esfuerzo para que todas estas políticas de realojamiento funcionaran y este gran esfuerzo ha sido reconocido internacionalmente.

\section{4.- CONCLUSIONES Y RECOMENDACIONES.}

De todo lo anteriormente analizado se obtienen varias conclusiones. Por una parte es imprescindible que las administraciones se conciencien de la ne- 
cesidad de la colaboración desinteresada en este tipo de políticas, sin necesariamente buscar la rentabilidad política. La realidad de estos años ha evidenciado que dicha colaboración en materia de política de realojamientos entre 1978 y 2011 ha sido fruto de la urgencia política y social por solucionar un problema, urbanístico, residencial y social más que de una actitud coparticipe frente al problema.

Desde 1978 hasta 2011 en la Comunidad de Madrid la relación entre Estado Central, Autonómico y Municipal ha pasado por diferentes fases y ha dado lugar a distintas actuaciones públicas en materia de realojamientos y política de vivienda social. El cronograma de colaboraciones podría resumirse en el cuadro 2.

Y por otra parte, después de 33 años de intervenciones en materia de realojamientos por parte de las administraciones, las realidad muestra que:

- Ninguna intervención podrá tener éxito si no se hace a partir de políticas transversales que combinen no sólo la intervención urbanística y residencial sino también medidas de actuación social.

- La urgencia en el desarrollo de políticas de intervención debería de venir marcada por la necesidad social y no únicamente por la necesidad de li-

\section{CuAdro 2}

CRONOGRAMA DE COLABORACIONES

\begin{tabular}{|c|c|c|c|}
\hline Etapa & Intervención & $\begin{array}{l}\text { Administraciones } \\
\text { que Colaboran }\end{array}$ & Tipo actuación \\
\hline 1978-1984 & $\begin{array}{l}\text { Operación Barrios en Re- } \\
\text { modelación }\end{array}$ & $\begin{array}{l}\text { Estado Central } \\
\text { Comunidad Autónoma } \\
\text { Ayuntamiento de la capital }\end{array}$ & $\begin{array}{l}\text { Urbanística } \\
\text { Residencial }\end{array}$ \\
\hline 1984-1985 & Propuesta AUI & Ayuntamiento de la capital & Residencial \\
\hline 1986-1998 & $\begin{array}{l}\text { Plan de Realojamiento } \\
\text { de Chabolistas de la } \\
\text { capital }\end{array}$ & $\begin{array}{l}\text { Comunidad Autónoma } \\
\text { Ayuntamiento de la capital } \\
\text { Estado Central } \\
\text { (puntualmente) }\end{array}$ & $\begin{array}{l}\text { Creación de un } \\
\text { Consorcio Residencial } \\
\text { Social }\end{array}$ \\
\hline $1998-2011$ & $\begin{array}{l}\text { Plan de Realojamiento } \\
\text { de Chabolistas de la Co- } \\
\text { munidad Autónoma }\end{array}$ & $\begin{array}{l}\text { Comunidad Autónoma } \\
\text { Ayuntamientos afectados } \\
\text { por el chabolismo de la } \\
\text { comunidad ( } 32 \text { programas } \\
\text { convenio) }\end{array}$ & $\begin{array}{l}\text { Creación del IRIS } \\
\text { Urbanística } \\
\text { Residencial Social }\end{array}$ \\
\hline
\end{tabular}

Fuente: Elaboración propia. 
berar los terrenos ocupados por las chabolas para la continuación del crecimiento urbano.

- El fenómeno chabolista tiene una enorme capacidad de regeneración hasta llegar a hacerse crónico por lo que la solución no puede ser únicamente residencial, si se pretende su desaparición.

- Con el realojamiento no desaparece el problema del chabolismo. Sin un acompañamiento social de la población, lo único que se conseguirá es trasladar el problema del chabolismo a pisos en altura normalizados, pero no se extinguirá.

- Sin la colaboración entre los tres niveles de la administración públia en esta materia será muy difícil, cuando no imposible, abordar con éxito los futuros brotes de chabolismo en las ciudades. Sin dicha colaboración no se podrá evitar el efecto frontera y/o el efecto llamada de los chabolistas hacia aquellos municipios que ofrezcan programas de realojamiento.

- Muchos ayuntamientos no tienen experiencia en realojamientos y necesitan el asesoramiento de la Comunidad, y todos el apoyo económico del Estado Central. Los enfrentamientos sólo llevan a la parálisis del proceso.

- Medidas como la creación del ASIVECAM, para el apoyo y seguimiento a las familias realojadas en vivienda en altura, es uno de los mejores ejemplos de buenas prácticas que se han llevado a cabo en los años que llevamos de democracia y sin sus actuaciones de mediación y apoyo a los afectados posiblemente muchos de los realojamientos hubieran fracasado.

- No es entendible que algunos ayuntamientos, como el de la capital, hayan decidido no utilizar los servicios del ASIVECAM y que ante esta decisión no hayan creado otros mecanismos similares de apoyo a las familias, desentendiéndose de ellas tras el realojamiento.

- ONGs, sindicatos, asociaciones vecinales, asociaciones gitanas deberían tener una presencia mucho más participativa y reivindicativa en la solución del problema chabolista y la integración social de sus afectados.

Si bien y como conclusión, se puede afirmar finalmente que aun cuando ha habido fallos y fracasos a lo largo del proceso, a pesar de los retrasos en la ejecución de las actuaciones, de las continuas críticas, de los ceses y destituciones, de las dimisiones, de los desencuentros institucionales continuos, a pesar de todo ello, si no hubiera sido por las intervenciones, primero del Plan de Barrios en Remodelación y posteriormente de las actuaciones del Consorcio y del IRIS, la realidad residencial de Madrid hoy día sería otra y posiblemente estaríamos ahora mismos lamentando el tiempo perdido sin saber que hacer 
con la ingente masa de población chabolista que ocuparía terrenos destinados a infraestructuras, servicios, espacio residencial, etc.

El chabolismo es un fenómeno complejo que posiblemente nunca llegue a extinguirse del todo, pero la experiencia de los años pasados evidencia que no sólo es un problema urbanístico, es un problema social. Si no se aborda la desaparición del chabolismo a través de programas de lucha contra la pobreza y la exclusión social, este nunca desaparecerá.

La chabola es sólo el reflejo externo, el más visible, de un problema mucho mas grave y profundo que tiene que ver con la falta de oportunidades. Las soluciones planteadas se centran más en aspectos urbanísticos y arquitectónicos que en aspectos sociales. Aunque es cierto que el alojamiento tiene un fuerte componente integrador no es suficiente. Una vivienda digna es sólo el comienzo. Un pilar más sobre el que se deben sustentar una política de realojamientos equilibrada.

Tan importante o más que una vivienda son las medidas sociales de inserción laboral que se deben tomar con los afectados, si de verdad se desea acabar con esta lacra social. Hasta que los políticos y la administración no entiendan que sin unos eficaces programas de inserción e integración social y laboral esta población no conseguirá salir de la pobreza, el chabolismo se hará crónico. El chabolismo evidencia más que una falta de alojamiento una falta de oportunidades y hasta que esto no se entienda nuestras urbes nunca se verán libres de él.

Fecha de recepción: 04/06/2013.

Fecha de aceptación: 07/10/2013.

\section{5.- BibliografíA}

Asociación Desarrollo Gitano (1979): "La Población Marginal Madrileña. Situación actual y criterios para lograr el realojamiento. Propuestas de actuación". Documento interno de la asociación, Madrid, 1979.

Asociación Desarrollo Gitano (1980): "Propuesta para el realojamiento de la población chabolista marginal de los distritos de Vallecas, Mediodía y Villaverde". Documento interno de la asociación, Madrid, 1980.

Asociación Desarrollo Gitano (1985): "El asentamiento chabolista de Vicálvaro. Censo de Población y alternativas al realojamiento". Documento interno de la asociación, Madrid, 1985.

Ayuntamiento de Madrid (1984): Propuestas AUI para la erradicación del chabolismo gitano de Madrid. Madrid, Área de Infraestructura y Urbanismo. 
Ayuntamiento de Madrid (1994): El chabolismo en el Municipio de Madrid. Situación y repercusiones sociourbanísticas. Un problema social para la población marginada. Un problema para todos los madrileños. Madrid, Gerencia Municipal de Urbanismo.

Ayuntamiento de Madrid (1998): Convenio de actuación entre el Ayuntamiento de Madrid y el Secretariado General Gitano. Plan de actuación para la atención a la población gitana en el Municipio de Madrid. Madrid, Gerencia Municipal de Urbanismo.

Asociación del Secretariado General Gitano (1998): Convenio de actuación para la atención a la población gitana. Madrid, Ayuntamiento de Madrid/Asociación del Secretariado General Gitano.

Comunidad de Madrid (1986): Convenio de colaboración para el realojamiento de la Población Marginada de Madrid. Madrid, Comunidad de Madrid/Ayuntamiento de Madrid.

Comunidad de Madrid (1988): Convenio de colaboración para el realojamiento de la Población Marginada de Madrid. Madrid, Comunidad de Madrid/Ayuntamiento de Madrid.

Comunidad de Madrid (1998): Documento de disolución, liquidación y extinción del Consorcio de la Población Marginada de Madrid. Resolución Final. Madrid, Consejería de Obras Públicas, Urbanismo y Transporte.

Comunidad de Madrid (2002): "Viviendas de integración social para la minoría étnica gitana en la Comunidad de Madrid (España)". IRIS, documentos internos.

Consorcio de la Población Marginada de Madrid (1986): "Acta de protocolización. Programas de Actuaciones del Consorcio para el Realojamiento de la Población Marginada de Madrid", en: Memorias de actuación, documentos internos, Madrid.

Consorcio de la Población Marginada de Madrid (1986 y sucesivos hasta 1998): "Memorias anuales de gestión”. Documentos internos, Madrid.

Consorcio de la Población Marginada de Madrid (1986): "Censo de 1986 de la población chabolista de Madrid". Documentos internos, Madrid.

Consorcio de la Población Marginada de Madrid (1988): "Informe general de actuaciones". Documentos internos, Madrid.

Consorcio de la Población Marginada de Madrid (1987): "Programa de acción social integral para Barrios de Tipología Especial y Asentamientos Provisionales". Documentos internos, Madrid.

Consorcio de la Población Marginada de Madrid (1980): "Programa de construcción de viviendas". Documentos internos, Madrid.

Consorcio de la Población Marginada de Madrid (1989): "Propuesta de suelo para el realojamiento de la población marginada de Madrid en Unidades de Realojamiento de Tipología Especial". Documentos internos, Madrid.

Consorcio de la Población Marginada de Madrid (1990): "Proyecto de seguimiento de familias realojadas en viviendas en altura". Documentos internos, Madrid.

Consorcio de la Población Marginada de Madrid (1993): "Estudio sobre el Consorcio de Población Marginada. Trabajo Social y Gestión Económica”. Documentos internos, Madrid. 
Consorcio de la Población Marginada de Madrid (1993): "Plan de erradicación urgente del chabolismo de Madrid". Documentos internos, Madrid.

Consorcio de la Población Marginada de Madrid (1996): "La acción social del Consorcio. Líneas Generales. Objetivos de programación cuatrienales 1996-1999”. Documentos internos, Madrid.

Consorcio de la Población Marginada de Madrid (1996): "Plan de realojamiento de la población censada 1996-1999". Documentos internos, Madrid.

EDIS (2000): Evaluación de los procesos de integración de las familias realojadas en la Comunidad de Madrid 1988-2000. Madrid, Instituto de Realojamiento e Integración Social.

IRIS (1998): "Documento de creación del IRIS. Chabolismo en la Comunidad de Madrid. Necesidad y Oportunidad de la Ley". Documentos internos del IRIS, Madrid.

IRIS (1999): "Acuerdo entre el IRIS y la Federación de Municipios de Madrid para facilitar la integración social de las familias excluidas socialmente mediante una distribución equitativa y homogénea". Documentos internos del IRIS, Madrid.

IRIS (1999 y sucesivos hasta 2006): "Memorias anuales". Documentos internos del IRIS, Madrid.

Instituto de Realojamiento e Integración Social (1999): Convenio para la atención e integración social de familias chabolistas. Madrid, Ayuntamiento de Madrid/Instituto de Realojamiento e Integración social.

Lago M. J. (1996): "Chabolismo y marginalidad residencial. El espacio residencial de las minorías étnicas". Tesis Doctoral inédita, Universidad Autónoma de Madrid.

Ministerio de Fomento (2000): La desigualdad urbana en España. Madrid, Dirección General de Programación Económica y Presupuestaria.

Noguez Saez, L. y Rodriguez, A. (2007): "El acompañamiento social de las familias gitanas con trayectoria de marginación y exclusión social”. Revista Documentación social, 145, pp. 133-152.

Noguez Saez, L. (2010): "Exclusión residencial y políticas públicas: El caso de la minoría gitana en Madrid". Tesis Doctoral, Universidad de Granada, Departamento de Antropología.

Servicio de Coordinación Legislativa y Relaciones Institucionales (1998): Ley de creación del Instituto de Realojamiento e Integración Social. Ley 16/1998, de 27 de octubre. Subdirección general de Régimen Jurídico y Desarrollo Normativo. SGT de Vicepresidencia. Consejería de Cultura y Deporte y Portavocia del Gobierno. Madrid, BOE de 6 de marzo 1999, BOE 56.

Palacios García, A. (2009): "Plata y Castañar (Villaverde, Madrid). Un ejemplo de Intervenciones en el Borde de la Ciudad. Urbanismo por y para el realojo". Papeles de Geografía, 49-50, pp. 115-131.

Palacios García, A. (2006): Barrios desfavorecidos urbanos. De la identificación a la intervención. Madrid como laboratorio. Madrid, Ediciones de la UAM.

Valenzuela, M. (1996): "Bienestar-malestar en las periferias urbanas", en L. Lopez Trigual (dir): Ciudad y alfoz. Centro y periferia Urbana. León, Secretariado de Publicaciones de la Universidad de León, pp. 25-42. 


\section{RESUMEN}

El proceso de concentración étnica del chabolismo se produce en Madrid desde el año 1986 hasta la actualidad. Esta situación desencadena la necesidad de colaboración entre las tres administraciones (central, autonómica y municipal). Nuestro estudio se centrará en el análisis de la evolución histórica de este proceso y de dicha colaboración.

La primera gran actuación contra el chabolismo en la capital fue la operación conocida como Barrios en Remodelación que tuvo lugar en 1989 e involucró la necesaria colaboración entre administraciones. Una vez realojadas todas estas familias el fenómeno del chabolismo sufrió un proceso de concentración étnica. El Ayuntamiento, a partir de enero 1984, desarrollo el conocido Plan de Acciones para la Erradicación del Chabolismo Gitano, sin mucho éxito en sus resultados. A partir de 1986, Ayuntamiento y Comunidad de Madrid se ven obligados a crear el Consorcio para el Realojamiento de la Población Marginada que finaliza sus actuaciones en 1999. En ese año es sustituido por el IRIS (Instituto de Realojamiento e Integración Social) cuyas actividades serán objeto de otro punto de análisis en esta investigación. Mostraremos como el IRIS estableció determinados cambios estratégicos fundamentales en el proceso de realojamientos que le diferenciarán de los planes de las etapas anteriores. Finalmente, veremos como tanto el Ayuntamiento como la Comunidad de Madrid han ido manteniendo a lo largo del tiempo posturas muy diferentes sobre las distintas medidas a adoptar frente al chabolismo y ello ha condicionado el mayor o menor éxito de las operaciones hasta el año 2010.

PAlabras Clave: chabolismo; infravivienda; realojamiento; inserción social; vivienda social; políticas transversales; traspaso de competencias.

\section{AbSTRACT}

The ethnic concentration process in shaty towns takes place in Madrid from the year 1986 until now. This situation unleashes the need of collaboration between three administrations (central, autonomous and municipal). Our study will be concentrate on the analysis of historical evolution of this process and of the above mentioned collaboration.

The first great action against the shanty towns in the capital was a program known as Neighborhoods in Remodeling that took place in 1989 and involved the necessary collaboration between administrations. Once rehoused all these families the phenomenon suffered a process of ethnic concentration. The Town Hall from January 1984 develop the acquaintance Plan of Actions for the Eradication of the gypsies shanty areas, without very much success in his results. From 1986, Town Hall and Community of Madrid are obliged to create a Consortium for the Rehousing of the Isolated Population who finishes his actions in 1999. In this year, that institution was replaced for IRIS (Institute of Rehousing and Social Integration) which activities will be an object of another point of analysis in this investigation. We will show as the IRIS established 
certain strategic fundamental changes in the process of rehousings the afected families that it will differ from the previous stages. Finally, we will see as so much the Town Hall as the Community of Madrid have been supporting, throughout the time, different positions on the measures to adopt opposite to the chabolismo and it has determined in major or minor success of the actions until the year 2010.

KEY WORDS: shanty town; marginal housing; rehousing, social insertion; social housing; housing policies; transfer of competitions.

\section{RÉSUMÉ}

Le processus de concentration ethnique du chabolismo se produit à Madrid dès le 1986 jusqu'à l'actualité. Cette situation déchaîne la nécessité de collaboration entre les trois administrations (centrale, autonome et municipale). Notre étude se concentrera sur l'analyse de l'évolution historique de ce processus et de la dite collaboration. Le premier grand comportement contre le chabolismo dans la capitale a été l'opération connue comme Quartiers dans une Rénovation qu'il a eue lieu en 1989 et a impliqué la collaboration nécessaire entre des administrations. Quand toutes ces familles ont été relogées le phénomène du chabolismo il a subi un processus de concentration ethnique.

Le Conseil municipal à partir de janvier 1984 Le, elle a développé, la connaissance Plan d'Actions pour l'Éradication du Chabolismo Gitano, sans beaucoup de succès dans ses résultats. À partir de 1986, le Conseil municipal et la Communauté de Madrid se voient obligé de créer l'Association pour le Relogement de la Population Margée qui finit ses rôles en 1999 .

Dans cette année il est substitué par l'ARC-EN-CIEL (Institut de Relogement et d'Intégration Sociale) dont les activités seront objet de l'autre point d'analyse dans cette recherche. Nous montrerons comme l'ARC-EN-CIEL a établi des changements déterminés stratégiques fondamentaux dans le processus de relogements qui il différeront des étapes antérieures. Finalement, nous verrons comme Conseil municipal et la Communauté de Madrid très différentes postures maintenaient le long du temps sur les mesures distinctes à adopter en face du chabolismo et cela est convenu dans un plus grand ou moindre succès des opérations jusqu'au 2010.

Mots CLÉs: une hutte; un bidon ville; un relogement; une insertion sociale; une demeure sociale; des transversales politiques; une cession de concurrences. 


\section{ANEXOS}

TABLA 1

FAMILIAS GITANAS REALOJADAS EN EL PROGRAMA DE BARRIOS EN REMODELACIÓN

\begin{tabular}{lc}
\hline Núcleo de procedencia de las familias & $N^{\text {o }}$ de familias realojadas \\
\hline Cornisa Orcasitas & 50 \\
Orcasitas & 69 \\
Orcasur & 80 \\
Palomeras & 70 \\
Pan Bendito & 200 \\
Pozo del Tío Raimundo & 100 \\
UVA Vallecas & 50 \\
UVA Villaverde & 75 \\
\hline Total & 694 \\
\hline
\end{tabular}

Fuente: Noguez Saez, 2010: "Exclusión residencial y políticas públicas: El caso de la minoría gitana en Madrid". Tesis Doctoral Universidad de Granada, Departamento de Antropología. 
TABLA 2

PROCESO DE CONCENTRACIÓN ÉTNICA DEL CHABOLISMO EN MADRID ENTRE 1979 Y 1984

\begin{tabular}{|c|c|c|c|c|}
\hline Distrito & $\begin{array}{c}\mathrm{N}^{\circ} \text { Chabolas } \\
\text { en } 1979\end{array}$ & $\begin{array}{c}\mathrm{N}^{\circ} \text { Familias } \\
\text { Gitanas en } 1979\end{array}$ & $\begin{array}{c}\mathrm{N}^{\circ} \text { Chabolas } \\
\text { en } 1984\end{array}$ & $\begin{array}{c}\mathrm{N}^{\circ} \text { Familias } \\
\text { Gitanas en } 1984\end{array}$ \\
\hline Retiro & 39 & 38 & 53 & 53 \\
\hline Chamartín & 1 & 1 & 45 & 45 \\
\hline Tetuán & 36 & 15 & 5 & 5 \\
\hline Fuencarral & 68 & 66 & 77 & 77 \\
\hline Moncloa & 0 & 0 & 50 & 50 \\
\hline Latina & 194 & 126 & 208 & 158 \\
\hline Carabanchel & 277 & 88 & 140 & 140 \\
\hline Villaverde & 365 & 117 & 67 & 35 \\
\hline Mediodía & 538 & 270 & 256 & 341 \\
\hline Vallecas & 82 & 38 & 12 & 12 \\
\hline C. Lineal & 20 & 13 & 10 & 10 \\
\hline San Blas & 187 & 183 & 380 & 378 \\
\hline Hortaleza & 0 & 0 & 98 & 98 \\
\hline TOTAL & 1.807 & 955 & 1.401 & 1.303 \\
\hline
\end{tabular}

Fuente: Lago, 1996: "Chabolismo y marginalidad residencial. El espacio residencial de las minorías étnicas". Tesis Doctoral inédita, Universidad Autónoma de Madrid. Datos originarios de las Memorias del Consorcio para el Realojamiento. 
TABLA 3

EVOLUCIÓN EN EL REALOJAMIENTO DE LOS CHABOLISTAS CENSADOS

EN 1986, DESCENSO DEL NÚMERO DE CHABOLAS ENTRE 1986 Y 1999

\begin{tabular}{ll}
\hline Año & No Chabolas \\
\hline 1986 & 2.192 \\
1987 & 2.674 \\
1988 & 2.619 \\
1989 & 2.384 \\
1990 & 1.967 \\
1991 & 1.569 \\
1992 & 1.143 \\
1993 & 922 \\
1994 & 795 \\
1995 & 674 \\
1996 & 594 \\
1997 & 265 \\
1998 & 101 \\
1999 & 66 \\
\hline
\end{tabular}

Fuentes: Datos de Censos y Memorias del Consorcio para el Realojamiento de la Población Marginada, Memoria Final de Actuaciones de 1998. Informe del IRIS 1999, documentos internos. 
TABLA 4

CENSO DE NUEVAS CHABOLAS EXISTENTES EN LA CAPITAL EN 1998

\begin{tabular}{|c|c|c|}
\hline DISTRITO & NUCLEO & $\mathrm{N}^{\circ}$ CHABOLAS \\
\hline Arganzuela & Estación Atocha & 5 \\
\hline \multirow[t]{2}{*}{ Barajas } & Avenida Logroño & 7 \\
\hline & Iberia-Río & 4 \\
\hline Chamartín & Rodríguez Jaén & 7 \\
\hline \multirow[t]{4}{*}{ Carabanchel } & Villalpando & 69 \\
\hline & Antonio Leyva & 40 \\
\hline & Tanatorio & 11 \\
\hline & La Chimenea & 5 \\
\hline \multirow[t]{3}{*}{ Fuencarral } & Quinta & 35 \\
\hline & Pitis & 130 \\
\hline & Liebres & 40 \\
\hline \multirow[t]{4}{*}{ Hortaleza } & Manoteras & 23 \\
\hline & Los Olivos & 13 \\
\hline & Cárcavas & 20 \\
\hline & Cristóbal Colón & 50 \\
\hline \multirow[t]{2}{*}{ Latina } & Mimbreras & 56 \\
\hline & Mica & 2 \\
\hline Moncloa & Puerta de Hierro & 24 \\
\hline \multirow[t]{4}{*}{ Puente de Vallecas } & Av. De la Albufera & 1 \\
\hline & Sta. Catalina & 80 \\
\hline & Trigales & 13 \\
\hline & La Celsa & 3 \\
\hline \multirow[t]{2}{*}{ San Blas } & Los Focos & 2 \\
\hline & Cocheras del Metro & 2 \\
\hline \multirow[t]{3}{*}{ Usera } & Carolinas & 35 \\
\hline & Huerto de San Fermín & 40 \\
\hline & Antonio López & 3 \\
\hline \multirow[t]{2}{*}{ Vicálvaro } & Cañaveral & 44 \\
\hline & Focos & 3 \\
\hline \multirow[t]{2}{*}{ Villa de Vallecas } & Pozo del Huevo & 127 \\
\hline & Cañada Real & 47 \\
\hline \multirow[t]{5}{*}{ Villaverde } & El Salobral & 250 \\
\hline & Crta. San Martin de la Vega & 3 \\
\hline & Camino del Molino & 4 \\
\hline & Ventero & 65 \\
\hline & Plata y Castañar & 3 \\
\hline 14 Distritos & 40 núcleos chabolistas & 1.550 chabolas \\
\hline
\end{tabular}

Fuente: Elaboración propia a partir de las Memorias del Consorcio, 1998. Informes del IRIS, documentos internos, 1999. 
TABLA 5

CENSO DE CHABOLAS UBICADAS EN OTROS AYUNTAMIENTOS DE LA COMUNIDAD DE MADRID EN 1998

\begin{tabular}{|c|c|c|}
\hline Municipio & Núcleo chabolista & $\mathrm{N}^{\circ}$ Chabolas \\
\hline Alcalá de Henares & Forjas & 10 \\
\hline Alcorcón & Vaquería de Cisneros & 7 \\
\hline Aranjuez & El Montecillo & 14 \\
\hline Boadilla del Monte & Finca Arroyo Pastores & 34 \\
\hline Galapagar & Río Guadarrama & 12 \\
\hline El Escorial & Vía del Ferrocarril & 2 \\
\hline Humanes & Av. Campohermoso & 23 \\
\hline \multirow[t]{2}{*}{ Majadahonda } & Finca del Marqués & 18 \\
\hline & Casa de Diego & 12 \\
\hline Mejorada del Campo & Camino de la Presa & 23 \\
\hline Moraleja de En Medio & Finca del Tío Pistolas & 1 \\
\hline Móstoles & Vereda del Pan y Agua & 67 \\
\hline \multirow[t]{2}{*}{ San Fernando de Henares } & Las Castellanas & 58 \\
\hline & Calle Segovia & 5 \\
\hline \multirow[t]{2}{*}{ San Sebastián de los Reyes } & Av. Valdelasfuentes & 3 \\
\hline & Caño Gordo & 2 \\
\hline \multirow[t]{3}{*}{ Torrejón de Ardoz } & Calle Solana & 4 \\
\hline & Cementerio & 2 \\
\hline & Los Castillos & 3 \\
\hline Velilla de San Antonio & Parque de la Cañada & 5 \\
\hline TOTAL & & 305 \\
\hline
\end{tabular}

Fuente: Elaboración Propia a partir de las Memorias del Consorcio, 1998. Informes del IRIS, documentos internos, 1999. 
TABLA 6

FAMILIAS A REALOJAR POR MUNICIPIO EN LA COMUNIDAD DE MADRID EN 1999, SEGÚN LOS ACUERDOS DEL IRIS CON LA FEDERACIÓN DE MUNICIPIOS MADRILEÑOS

\begin{tabular}{|c|c|c|}
\hline Municipio & $\begin{array}{c}\mathrm{N}^{\circ} \text { de familias } \\
\text { a realojar }\end{array}$ & $\begin{array}{c}\text { \% que representaban } \\
\text { sobre el total población } \\
\text { del municipio }\end{array}$ \\
\hline Ajalvir & 1 & 0,003 \\
\hline Alcalá de Henares & 71 & 3,25 \\
\hline Alcobendas & 36 & 1,65 \\
\hline Alcorcón & 61 & 2,82 \\
\hline Algete & 5 & 0,25 \\
\hline Arganda del Rey & 13 & 0,58 \\
\hline Arroyomolinos & 1 & 0,05 \\
\hline Boadilla del Monte & 8 & 0,35 \\
\hline Brunete & 2 & 0,08 \\
\hline Ciempozuelos & 5 & 0,25 \\
\hline Cobeña & 1 & 0,04 \\
\hline Collado Villalba & 16 & 0,74 \\
\hline Colmenar Viejo & 12 & 0,56 \\
\hline Colmenarejo & 2 & 0,07 \\
\hline Coslada & 33 & 1,51 \\
\hline Daganzo & 1 & 0,05 \\
\hline Fuenlabrada & 71 & 3,26 \\
\hline Galapagar & 7 & 0,33 \\
\hline Getafe & 62 & 2,85 \\
\hline Griñón & 2 & 0,07 \\
\hline Hoyo de Manzanares & 2 & 0,1 \\
\hline Humanes & 4 & 0,17 \\
\hline Las Rozas de Madrid & 20 & 0,9 \\
\hline Leganés & 75 & 3,48 \\
\hline Loeches & 1 & 0,05 \\
\hline
\end{tabular}

Fuente: Elaboración propia a partir de los datos de los Convenios-Programas entre la Federación de Municipios de Madrid y el IRIS. 
TABLA 6 (continuación)

FAMILIAS A REALOJAR POR MUNICIPIO EN LA COMUNIDAD DE MADRID EN 1999, SEGÚN LOS ACUERDOS DEL IRIS CON LA FEDERACIÓN DE MUNICIPIOS MADRILEÑOS

\begin{tabular}{|c|c|c|}
\hline Municipio & $\begin{array}{c}\mathrm{N}^{0} \text { de familias } \\
\text { a realojar }\end{array}$ & $\begin{array}{c}\text { \% que representaban } \\
\text { sobre el total población } \\
\text { del municipio }\end{array}$ \\
\hline Madrid (capital) & 1340 & 61,89 \\
\hline Majadahonda & 17 & 0,8 \\
\hline Mejorada del Campo & 6 & 0,29 \\
\hline Moraleja de Enmedio & 1 & 0,05 \\
\hline Móstoles & 85 & 3,91 \\
\hline Navacerrada & 5 & 0,23 \\
\hline Paracuellos de Jarama & 2 & 0,11 \\
\hline Parla & 30 & 1,38 \\
\hline Pinto & 11 & 0,5 \\
\hline Pozuelo de Alarcón & 26 & 1,2 \\
\hline Rivas-Vaciamadrid & 10 & 0,45 \\
\hline San Agustín de Guadalix & 2 & 0,09 \\
\hline San Fernando de Henares & 13 & 0,59 \\
\hline San Martín de la Vega & 4 & 0,18 \\
\hline San Sebastián de los Reyes & 25 & 1,15 \\
\hline Torrejón de Ardoz & 38 & 1,77 \\
\hline Torrejón de la Calzada & 1 & 0,06 \\
\hline Torrejón de Velasco & 1 & 0,03 \\
\hline Torrelodones & 5 & 0,21 \\
\hline Tres Cantos & 12 & 0,55 \\
\hline Valdemoro & 9 & 0,42 \\
\hline Velilla de San Antonio & 2 & 0,09 \\
\hline Villanueva de la Cañada & 3 & 0,16 \\
\hline Villanueva del Pardillo & 1 & 0,06 \\
\hline Villaviciosa de Odón & 7 & 0,34 \\
\hline
\end{tabular}

Fuente: Elaboración propia a partir de los datos de los Convenios-Programas entre la Federación de Municipios de Madrid y el IRIS. 